\title{
Core-level spectra and binding energies of transition metal nitrides by non-destructive $x$ - ray photoelectron spectroscopy through capping layers
}

Grzegorz Greczynski, D. Primetzhofer, Jun Lu and Lars Hultman

\section{Journal Article}

\section{Tweet}

N.B.: When citing this work, cite the original article.

Original Publication:

Grzegorz Greczynski, D. Primetzhofer, Jun Lu and Lars Hultman, Core-level spectra and binding energies of transition metal nitrides by non-destructive $\mathrm{x}$-ray photoelectron spectroscopy through capping layers, Applied Surface Science, 2017. 396, pp.347-358. http://dx.doi.org/10.1016/j.apsusc.2016.10.152

Copyright: Elsevier

http://www.elsevier.com/

Postprint available at: Linköping University Electronic Press

http://urn.kb.se/resolve?urn=urn:nbn:se:liu:diva-136167

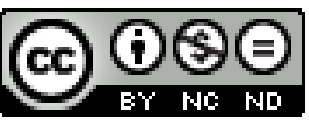

LINKÖPINGS

UNIVERSITET 


\title{
Core-level spectra and binding energies of transition metal nitrides by non-destructive $x$-ray photoelectron spectroscopy through capping layers
}

\author{
G. Greczynski, ${ }^{1}$ D. Primetzhofer, ${ }^{2}$ J. Lu, ${ }^{1}$ and L. Hultman ${ }^{1}$ \\ ${ }^{1}$ Thin Film Physics Division, Department of Physics (IFM), Linköping University, \\ SE-581 83 Linköping, Sweden \\ ${ }^{2}$ Department of Physics and Astronomy, The Ångström Laboratory, Uppsala University, \\ P.O. Box 516, SE-75120 Uppsala, Sweden
}

\begin{abstract}
We present the first measurements of $x$-ray photoelectron spectroscopy (XPS) core level binding energies (BE's) for the widely-applicable group IVb-VIb polycrystalline transition metal nitrides (TMN's) TiN, VN, CrN, ZrN, NbN, MoN, HfN, TaN, and WN as well as AlN and SiN, which are common components in the TMN-based alloy systems. Nitride thin film samples were grown at $400{ }^{\circ} \mathrm{C}$ by reactive dc magnetron sputtering from elemental targets in $\mathrm{Ar} / \mathrm{N}_{2}$ atmosphere. For XPS measurements, layers are either (i) $\mathrm{Ar}^{+}$ion-etched to remove surface oxides resulting from the air exposure during sample transfer from the growth chamber into the XPS system, or (ii) in situ capped with a few nm thick Cr or $\mathrm{W}$ overlayers in the deposition system prior to air-exposure and loading into the XPS instrument. Film elemental composition and phase content is thoroughly characterized with time-of-flight elastic recoil detection analysis (ToF-E ERDA), Rutherford backscattering spectrometry (RBS), and $x$-ray diffraction. High energy resolution core level XPS spectra acquired with monochromatic Al $\mathrm{K} \alpha$ radiation on the ISO-calibrated instrument reveal that even mild etching conditions result in the formation of a nitrogen-deficient surface layer that substantially affects the extracted binding energy values. These spectra-modifying effects of $\mathrm{Ar}^{+}$ion bombardment increase with increasing the metal atom mass due to an increasing nitrogen-to-metal sputter yield ratio.

The superior quality of the XPS spectra obtained in a non-destructive way from capped TMN films is evident from that numerous metal peaks, including Ti 2p, V 2p, Zr 3d, and Hf 4f, exhibit pronounced satellite features, in agreement with previously published spectra from
\end{abstract}


layers grown and analyzed in situ. In addition, the N/metal concentration ratios are found to be 25-90\% higher than those obtained from the corresponding ion-etched surfaces, and in most cases agree very well with the RBS and ToF-E ERDA values. The N 1s BE's extracted from capped TMN films, thus characteristic of a native surface, show a systematic trend, which contrasts with the large BE spread of literature "reference” values.

Hence, non-destructive core level XPS employing capping layers provides an opportunity to obtain high-quality spectra, characteristic of virgin in situ grown and analyzed TMN films, although with larger versatility, and allows for extracting core level BE values that are more reliable than those obtained from sputter-cleaned N-deficient surfaces. Results presented here, recorded from a consistent set of binary TMN's grown under the same conditions and analyzed in the same instrument, provide a useful reference for future XPS studies of multinary materials systems allowing for true deconvolution of complex core level spectra.

Keywords: TiN, XPS, magnetron sputtering, binding energy, VN, CrN, NbN, ZrN, MoN, HfN, TaN, WN, AlN, SiN, 


\section{Introduction}

X-ray photoelectron spectroscopy (XPS) is a basic research tool to identify surface chemistry and composition of various compounds in bulk or thin film form. Transition metal nitride (TMN)-based compouds attract tremendous scientific and technological interest due to their unique combination of properties often combining ceramics (high hardness) with metallic (high conductivity), which make them ideal candidates for applications as wear-resistant coatings on cutting tools ${ }^{1,2}$ and engine components, ${ }^{3,4}$ as well as diffusion barriers in electronic devices. ${ }^{5,6}$ In recent years trend is to improve properties even further by going to multinary nitrides with the classical (most studied) example of TiAlN, ${ }^{7}$ where alloying with Al leads to the formation of metastable system and brings a range of benefits like improved hightemperature oxidation resistance, ${ }^{8}$ higher hardness, ${ }^{9}$ and favorable phase transformation at high temperature. $^{10}$

Interpretation of XPS spectra obtained from multinary TMNs is, however, very challenging due to an increased complexity of core level spectra, which are often non-trivial to interpret even in the case of binary systems (e.g. Ti 2p spectra of TiN). ${ }^{11}$ This fact makes the task of an unambiguous bonding structure assignment extremely cumbersome, if not impossible. In addition, the majority of TMN films intended for XPS analyses require some form of in situ cleaning prior to spectra acquisition to remove surface oxides and contaminants, which is typically done by sputtering, employing noble gas ions like $\mathrm{Ar}^{+}$with energy in the range from 0.5 to $4 \mathrm{keV}$. This approach is commonly used in reported XPS studies of TMN surfaces despite the well-known destructive effects of ion bombardment like cascade mixing, chemical reduction, recoil implantation, segregation, surface roughening, preferential sputtering, redeposition of sputtered material, radiation damage, and forward implantation of surface 
species, to name a few. ${ }^{12}$ Another very evident problem during the deconvolution of complex core level signals is a large spread of reported binding energy (BE) values. For example, the NIST data base ${ }^{13}$ contains 20 entries for TiN with the Ti 2p $3 / 2$ BE varying from 454.77 to $455.80 \mathrm{eV}$ and $\mathrm{N}$ 1s from 396.9 to $397.8 \mathrm{eV}$, which clearly illustrates the problem and prevents unambiguous assignment of observed spectral features. The situation is even worse for a nonconducting compound like $\mathrm{Si}_{3} \mathrm{~N}_{4}$ in which case Si 2p BE changes by $1.5 \mathrm{eV}$, from 100.6 to $102.1 \mathrm{eV}$. The main factors responsible for these discrepancies are both, instrument- and sample-related and include: (i) inconsistent BE referencing (C 1s, Ar 2p $3 / 2$, or Fermi Level), (ii) differences in surface preparation methods (often by means of destructive $\mathrm{Ar}^{+}$ion etching), (iii) differences in film composition, microstructure, and/or phase content resulting from insufficient characterization, and (iv) surface charging (affected by layer thickness, sample mounting, $x$-ray source power, flood gun settings, etc.).

In addition, apart from widely-studied TiN and CrN systems, for many TM-based nitrides available XPS BE reference data are very limited (WN, VN, HfN) or simply of a very poor quality. Comparative XPS studies are limited to 2-3 TMN materials systems, ${ }^{14,15}$ often prepared by different methods.

To resolve the issues discussed above, we present results of systematic core level XPS studies for the most relevant, group IVb-VIb, TMN thin films grown by magnetron sputtering including TiN, VN, CrN, ZrN, NbN, MoN, HfN, TaN, and WN. For completeness, AlN and SiN, as common components in multinary alloy systems, are also included in the comparison. High-energy resolution core-level spectra are acquired from samples that are in situ capped, immediately after the film growth, with a few nm thick metal overlayer prior to air-exposure necessary to transfer samples from the growth chamber into the ultrahigh-vacuum (UHV) XPS instrument, a technique that was recently shown to allow for a non-destructive acquisition of high-resolution core-level spectra representative of clean surfaces. ${ }^{16}$ In addition, corresponding 
spectra obtained after $\mathrm{Ar}^{+}$ion etching are presented to visualize the large extent of ion bombardment-induced damage, often not realized as the reference spectra are neglected or not available. For most materials systems, even mild etching conditions (low energy $0.5 \mathrm{keV} \mathrm{Ar}^{+}$ ions incident at the shallow angle of $70^{\circ}$ from the surface normal) result in severe $\mathrm{N}$ loss, which affects $\mathrm{N} 1$ s as well as metal core-level spectra and, hence, extracted binding energies. On the contrary, XPS spectra obtained in a non-destructive way from metal-capped layers are characteristic of a native nitride surface: N/metal ratios are $25-90 \%$ higher than those obtained from sputter-cleaned layers, while numerous metal peaks exhibit pronounced satellite features, in agreement with the in situ grown and analyzed layers. Thus, results of non-destructive XPS studies performed here in a consistent way on the set of well-characterized TMN layers provide a solid reference data base, which allows for more reliable BE referencing and spectra deconvolution in TMN-based multinary systems.

\section{Experimental}

Polycrystalline TMN thin film layers of AlN, SiN, TiN, VN, CrN, ZrN, NbN, MoN, HfN, TaN, and WN are grown from rectangular $8.8 \times 50 \mathrm{~cm}^{2}$ elemental targets by reactive dc magnetron sputtering (DCMS) in Ar/ $\mathrm{N}_{2}$ gas mixtures employing a CC800/9 CemeCon AG system. ${ }^{17}$ The total pressure $P_{\text {tot }}$ during all depositions is kept constant at 3 mTorr (0.4 Pa), while the $\mathrm{N}_{2}$-to-Ar flow ratio is optimized for each target material to obtain stoichiometric single-phase layers, and ranges from 0.18 with highly reactive targets like Ti, $\mathrm{Al}$, and Si to 3.3 with Cr. Si(001) substrates previously cleaned in acetone and isopropanol are biased at $-60 \mathrm{~V}$ and mounted $18 \mathrm{~cm}$ away from the target surface. The average target power is $2 \mathrm{~kW}$, while the resulting film thickness is intentionally relatively low, from $140 \mathrm{~nm}$ for TiN to $420 \mathrm{~nm}$ for WN, to minimize surface roughness (see Tab. 1). ${ }^{18}$ The heating is accomplished with two resistive heaters operating at $8.8 \mathrm{~kW}$ each, ensuring the substrate temperature $T_{s}$ of $470 \pm 12{ }^{\circ} \mathrm{C}$. 
In the case of capped samples, following TMN growth, $f_{N 2}$ is set to zero while $f_{A r}$ is increased to $400 \mathrm{~cm}^{3} / \mathrm{min}$ to maintain $P_{\text {tot }}=0.4 \mathrm{~Pa}$; the second, $\mathrm{Cr}$ or $\mathrm{W}$, target, intended for cap layer deposition, is sputter-cleaned for $120 \mathrm{~s}$ at $2 \mathrm{~kW}$ behind closed shutters, after which power is reduced to $0.3 \mathrm{~kW}$ in the case of Cr-cap deposition or to $0.6 \mathrm{~kW}$ for $\mathrm{W}$-cap growth. Capping overlayers are deposited with thicknesses ranging from 2 to $4 \mathrm{~nm}$, as estimated from the attenuation of core level signals using electron inelastic mean free paths reported by Tanuma et al. ${ }^{19}$

All films are exposed to the laboratory atmosphere at very similar venting temperatures $T_{V}$ $=230 \pm 20^{\circ} \mathrm{C}$ in order to avoid significant influence of $T_{v}$ on the thickness of formed surface oxide layer, ${ }^{20}$ and subsequently transferred to the load-lock chamber of the UHV XPS system. The total air exposure time is shorter than 2 min.

Metal 2p, 3d, and 4f core-level XPS spectra as well as N 1s, O 1s, and C 1s signals are obtained from TMN films in an Axis Ultra DLD instrument from Kratos Analytical (UK). The base pressure in the system during spectra acquisition is $1.1 \times 10^{-9}$ Torr. Monochromatic $\mathrm{Al} \mathrm{K \alpha}$ radiation $(\mathrm{hv}=1486.6 \mathrm{eV})$ is used and the anode power is set to $150 \mathrm{~W}$. All spectra are collected from the area of $0.3 \times 0.7 \mathrm{~mm}^{2}$ and at normal emission angle. To minimize the effect of instrument/sample instabilities over the acquisition time, the multi-sweep spectra recording is performed in parallel for all core levels rather than in a sequence. Spectrometer BE scale is calibrated according to the ISO standards, as described in Sect.3.2 below. The analyzer pass energy is set to $20 \mathrm{eV}$, which yields the full width at half maximum of $0.55 \mathrm{eV}$ for the $\mathrm{Ag} 3 \mathrm{~d}_{5 / 2}$ peak. Spectra deconvolution and quantification are performed using the CasaXPS software package. ${ }^{21}$ For each materials system, two sets of core-level spectra are acquired, one from asgrown samples capped with thin, XPS-transparent, metal capping layers (referred to as "nondestructive” data) and one from uncapped films sputter-cleaned in situ in the spectrometer with $0.5 \mathrm{keV} \mathrm{Ar}^{+}$ions incident at $70^{\circ}$ from the surface normal. In the case of insulating $\mathrm{AlN}$ and 
SiN films with no metal capping a low-energy electron flood gun is employed to compensate for surface charging during spectra acquisition.

As-deposited TMN film compositions are determined free of standards by time-of flight energy elastic recoil detection analyses (ToF-E ERDA) and Rutherford Backscattering Spectrometry (RBS). RBS also provides atomic areal densities for the thin films investigated. All ion scattering experiments were performed at the tandem accelerator laboratory at Uppsala University employing a 5MV NEC instrument. For ToF-E ERDA a $36 \mathrm{MeV}^{127} \mathrm{I}^{8+}$ probe beam is incident at $67.5^{\circ}$ with respect to the sample surface normal; recoils are detected at $45^{\circ}$. Evaluation was performed using the CONTES software. ${ }^{22}$ Systematic uncertainties arise mainly from the stopping power of projectile and recoil ions as well as detection efficiencies different from unity for light species. ${ }^{23}$ For the present system, uncertainties are expected to be typically lower than $5 \%$ of the respective concentrations in nitrogen and metals species. In RBS backscattered ions are detected by a solid state detector situated at an angle of $170^{\circ}$ with respect to the incident beam axis. The uncertainty in deduced composition is determined by counting statistics due to low scattering cross sections for $\mathrm{N}$ and the nitrogen and the silicon backing signal overlap. Thus, RBS results can only indicate significant deviations from the unity metal-to-non-metal ratio, they are, however, expected to be less prone to systematic errors. Samples for cross-sectional transmission electron microscopy (TEM) and high-resolution TEM (HR-TEM) analyses are prepared by mechanical polishing, followed by $\mathrm{Ar}^{+}$ion milling at 5 $\mathrm{kV}$ with an $8^{\circ}$ incidence angle and sample rotation. During the final thinning stages, the ion energy and incidence angle are reduced to $2.5 \mathrm{kV}$ and $5^{\circ}$. Film microstructure is analyzed in an FEI Tecnai G2 TF 20 UT transmission electron microscope operated at $200 \mathrm{kV}$. Layer thicknesses are measured by cross-sectional scanning electron microscopy (SEM) in a Zeiss LEO 1550 instrument. Root mean square (RMS) surface roughness is based on $2 \times 2 \mu \mathrm{m}^{2}$ topographical maps obtained by tapping-mode atomic force microscopy (AFM) employing a 
TI 950 Hysitron system. A Philips X'Pert MRD system operated with point-focused Cu Ka radiation is employed for $\theta-2 \theta x$-ray diffraction (XRD) scans to obtain information about crystalline phases present and determination of relaxed lattice constants from $\theta-2 \theta$ scans acquired at the strain-free tilt angle. ${ }^{24}$

\section{Results and Discussion}

\subsection{Film phase content and nanostructure}

All films are thoroughly characterized with respect to crystalline content by $\theta-2 \theta$ XRD scans, in some more complex cases where many phases may coexist (e.g., TaN, HfN, and MoN), performed also as a function of the angle between the sample surface normal and the diffraction plane containing the incoming and diffracted $x$-ray beams, ${ }^{25}$ to reveal crystallites with all possible orientations. With the exception of SiN films, which are $x$-ray amorphous, all other layers are polycrystalline. Results summarized in Tab.1 indicate that the majority of TMN films including TiN, VN, CrN, ZrN, NbN, and HfN are single-phase cubic with NaCl-crystal structure. The lattice parameters extracted from 002 reflections $a_{o}$ agree to within $\pm 0.04 \AA$ with powder diffraction data. ${ }^{26}$ AIN layers are single-phase hexagonal structure with complete 0002 out-of-plane orientation. ${ }^{27} \mathrm{MoN}$ layers exhibit peaks from the expanded $\gamma-\mathrm{Mo}_{2} \mathrm{~N}$ face-centered cubic phase with random distribution of nitrogen in octahedral sites $\left(a_{o}=4.24 \AA\right.$ vs $4.16 \AA$ for bulk samples) and weak reflections due to hexagonal MoN phase (less than $2 \%$ ). ${ }^{28} \mathrm{TaN}$ films are dominated by the expanded cubic NaCl-structure phase ( $a_{o}=4.43 \AA$ vs $4.33 \AA$ for bulk samples), ${ }^{29}$ and contain small amounts $(<5 \%)$ of secondary phases including orthorhombic $\mathrm{Ta}_{3} \mathrm{~N}_{5}$, tetragonal Ta $\mathrm{N}_{5}$, and hexagonal TaN. XRD diffractograms obtained from WN films give evidence for single-phase cubic $\mathrm{W}_{2} \mathrm{~N}$ with expanded lattice as compared to the reference powder diffraction data (4.24 $\AA$ vs $4.13 \AA$ ). ${ }^{30}$ The preferred out-of-plane orientations PO, are also listed in Tab. 1. 
Transmission electron microscopy characterization is used to determine the film's microstructure, here exemplified with the NbN film. Cross-sectional bright-field TEM and HRTEM images are shown in Figures 1(a)-(b) together with selected area electron diffraction (SAED) pattern. The NbN layer exhibits columnar nanostructure consisting of densely-packed columns with an average diameter of $100 \pm 50 \AA$. There is no evidence for intra-columnar or inter-columnar porosity. SAED pattern shown as an insert in Fig 1(a) indicates 002 preferred orientation, in agreement with XRD results discussed above. The other nitride films also exhibited dense nanocolumnar structures.

\subsection{Film composition}

The XPS-derived N/metal ratios obtained from TMN film surfaces capped with metal overlayers as well as from uncapped $\mathrm{Ar}^{+}$-etched surfaces are plotted in Figure 2 together with bulk compositions obtained from ToF-E ERDA. All results are also summarized in Table 1, along with detected contaminants and RBS-derived N/metal ratios. The latter results, believed to be less accurate than ToF-E ERDA, are omitted in Fig. 2 for the sake of clarity of data presentation. Nevertheless, N/metal ratios obtained from both bulk-probing techniques are essentially the same.

In general, there is a good agreement between ToF-E ERDA and XPS ratios from capped samples, especially given the $\pm 5 \%$ error bar involved. Larger deviations are observed only for AlN and TaN. One has to realize, however, that in general XPS compositions being characteristic of the surface region do not necessarily need to reflect those obtained with the bulk-probing techniques, as thermodynamics and/or the synthesis process may lead to severe concentration gradients on a few nm length scale.

Equally importantly, the XPS results shown in Fig. 2 indicate that even a very gentle $\mathrm{Ar}^{+}$ion etching (low energy and shallow incidence angle) results in significant $\mathrm{N}$ loss for all materials systems. The $\mathrm{N}$ loss is smallest for AlN (21\%) and tends to increase with increasing 
TM mass to $47 \%$ in the case of HfN. This trend can be rationalized by the fact that the nitrogento-metal sputter yield ratio $\gamma_{N} / \gamma_{T M}$ also increases with TM mass, as revealed by the results of Monte-Carlo based TRIM (Transport of Ions in Matter) ${ }^{31}$ simulations performed for $0.5 \mathrm{keV}$ $\mathrm{Ar}^{+}$ions incident at an angle of $70^{\circ}$ from surface normal, and summarized in Tab. 1 . Detailed analysis is, however, complicated as the thickness of the ion-modified surface layer also varies between different materials systems studied. Such significant change in the composition of the surface layer has a large influence on the XPS core level spectra as the probing depth with commonly employed $x$-rays ( $\mathrm{Al} \mathrm{K} \alpha$ or $\mathrm{Mg} \mathrm{K \alpha}$ ) is not much longer than the thickness of the ion-modified layer. Section 3.5 below contains numerous examples on how destructive the $\mathrm{Ar}^{+}-$ ion etch is to TMN surfaces.

\subsection{Capping layers}

As the vast majority of vacuum systems used to grow TMN thin films do not have in situ XPS capabilities, the surfaces get oxidized and contaminated with adventitious carbon during storage and/or transport in the ambient atmosphere. This undesired surface modification makes it cumbersome for reliable XPS analyses that have an ambition to present data characteristic of as-grown films. $\mathrm{Ar}^{+}$-ion etch is extensively used to clean as received surfaces despite the wellknown destructive effects of such procedure. ${ }^{12}$ As shown in Sect. 3.5 even with mild etching conditions (low ion energy and shallow incidence angle) the effects of ion bombardment are present in XPS spectra of TMN layers.

We recently showed that the destructive effects of ion etching can be avoided by using very thin ( 2 nm), XPS-transparent, $\mathrm{Al}$ capping layers to prevent oxidation of polycrystalline TiN film surfaces during transport in air from a magnetron sputtering system into the XPS instrument. ${ }^{16}$ The Ti 2p and N 1s high-resolution core-level spectra acquired from such samples were identical to those obtained from single-crystal TiN/MgO(001) films grown and analyzed 
in situ in a UHV XPS system. Moreover, the XPS-derived N/Ti ratio was in a very good agreement with RBS and ToF-E ERDA results, and significantly higher than the value obtained from $\mathrm{Ar}^{+}$-etched surfaces.

The following criteria are relevant for the choice of a proper capping layer: (i) heat of nitride formation $\Delta_{f} H^{0}$ for the capping layer metal should be minimized and lower than that of the TMN to be studied $\left(\Delta_{f} H_{c a p}^{0}<\Delta_{f} H_{T M N}^{0}\right)$ to avoid interfacial reactions that might be triggered by $x$-ray exposure, (ii) the capping layer should form a stable oxide, and (iii) core-level peaks from the capping layer should not overlap with the primary TMN signals. The capping layer thickness is a compromise between the requirement of electron transparency (determined by electron mean free path) and thickness of a native oxide layer formed during the air exposure time. Table 1 includes the relevant $\Delta_{f} H_{T M N}^{0}$ data along with details of capping layers applied for each TMN studied. For WN $\Delta_{f} H_{W N}^{0}=-17 \mathrm{~kJ} / \mathrm{mol}$ is so low that no proper cap can be applied.

Quantitative analyses of capped films require that recorded core levels intensities are corrected for the inelastic scattering of TMN electrons in the metal overlayers. The original signal gets attenuated by an exponential factor $\sim \exp \left(-d / \lambda\left(E_{k i n}\right)\right)$, in which $d$ is the capping layer thickness and $\lambda\left(E_{k i n}\right)$ stands for the inelastic electron mean free path. Since the latter is a function of electron kinetic energy, it is in general favorable for better accuracy of elemental composition, to base quantification on core level peaks with a minimum BE separation.

For each sample, the capping layer thickness is determined from the attenuation of TMN peaks and ranges from 20 to $26 \AA$ for $\mathrm{Cr}$ caps and from 27 to $40 \AA$ for W caps (see Tab.1). Thus, for all films the capping layer thickness exceeds the root-mean-square surface roughness as determined by AFM measurements (see Tab. 1). Cr 2p and W 4f spectra from capping layers indicate, in addition to oxide, also a metallic component, ensuring that the entire capping layer was not oxidized during transport to the XPS instrument. 
The potential of capping layers for reliable quantification is illustrated in Fig. 3, where the XPS-derived N/Cr ratio is plotted for the W-capped CrN film as a function of sputtering time $t$. Initially, $\mathrm{N} / \mathrm{Cr}=0.99$ with $t<1$ min, which corresponds very well with the bulk composition (see Tab.1) indicating that the capping layer is intact. This behavior is expected due to low $\mathrm{Ar}^{+}$ ion energy $0.5 \mathrm{keV}$ and shallow incidence angle of $70^{\circ}$ used, since both result in relatively short range of collision cascades that according to TRIM estimates do not exceed $12 \AA$, hence much less than the W-cap thickness (40 A). Further sputtering, $1<t<6$ min., leads to gradual drop in $\mathrm{N} / \mathrm{Cr}$ associated with the removal of the $\mathrm{W}$-capping layer. Eventually, with $t>6 \mathrm{~min}$. the capping is completely gone and the $\mathrm{N} / \mathrm{Cr}$ ratio saturates at $\sim 0.55$, i.e., well below the bulk composition. The preferential resputtering of lighter $\mathrm{N}$ atoms is thus evident even with the mild etching conditions, and, thus, all results from ion-etched TMN surfaces widely reported should be treated with a great deal of caution.

Another benefit of capping layers becomes evident during analyses of poorly conducting samples. The thin metal overlayers possessing non-oxidized components while exposed to $x$ rays act as a source of photoelectrons, which are sufficient to prevent a positive charge buildup in the surface region of the non-conducting film. Thus, XPS spectra can be acquired without using external charge compensation which is typically detrimental to spectra quality and may lead to artefacts when non-homogenous films are analyzed.

\subsection{Binding energy reference}

One of the main reasons for the observed spread in tabulated BE values for the same chemical species is problems with proper and consistent binding energy scale reference. To avoid uncertainties related to using the $\mathrm{C}$ 1s signal from adventitious carbon as the energy reference $^{32,33}$ we applied the following procedure. In the first step, $\mathrm{Au} 4 \mathrm{f}_{7 / 2}, \mathrm{Ag} 3 \mathrm{~d}_{5 / 2}$, and $\mathrm{Cu}$ $2 \mathrm{p}_{3 / 2}$ peak positions obtained from sputter-cleaned foils are determined with respect to the Fermi level (FL) cut-off. ${ }^{34}$ For all three core-levels, we find that the peak positions are shifted 
by $\Delta \mathrm{E}=0.08 \mathrm{eV}$ towards higher $\mathrm{BE}$ with respect to the recommended ISO standards for

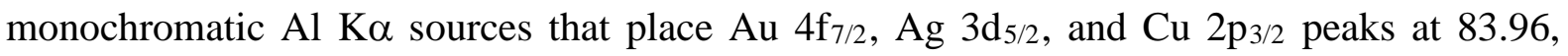
368.21, and $932.62 \mathrm{eV}$, respectively. ${ }^{35,36}$ Next, for each TMN sample the highest kinetic energy portion of the valence band spectra around the Fermi energy is recorded to determine the position of core level peaks with respect to the Fermi level cut-off. Finally, the $\Delta \mathrm{E}$ correction is applied for all BE values quoted in this work to comply with the ISO standards. This procedure also helps avoid the $\mathrm{BE}$ referencing problems resulting from the fact that $\mathrm{C} 1 \mathrm{~s} \mathrm{BE}$ depends on the type of surface oxides formed during venting procedure. ${ }^{20}$ The $\mathrm{BE}$ of the $\mathrm{Ar}$ 2p $3 / 2$ peak present in all $\mathrm{Ar}^{+}$-etched films was also found to vary depending on the materials system, excluding this signal as a reliable BE reference.

The BE referencing procedure outlined above is obviously limited to films that exhibit pronounced FL cut-off. For semiconducting or insulating layers, like AlN or SiN, we use the metal Cr signal from the capping layer as an internal BE reference. Then, spectra from corresponding films without capping layers that require external charge compensation during measurement, are aligned to the signals from the capped samples.

ISO-calibrated BE values for $\mathrm{N}$ 1s and TMN core levels obtained from capped films are listed in Tab. 2.

\subsection{Core-level spectra}

In this section, due to the length constraints, the most interesting core level signals from capped TMN films are directly compared to those obtained from sputter-cleaned surfaces. Figures 4(a)-(h) show the main metal core levels for TiN, VN, CrN, ZrN, NbN, MoN, HfN, and TaN, while Figs. 5(a)-(f) include N 1s spectra for TiN, CrN, ZrN, MoN, HfN, and TaN. All metal lines are normalized to the intensity of the highest feature, whereas $\mathrm{N} 1$ s spectra are normalized to the corresponding metal signal to facilitate direct comparison between spectra 
obtained from capped and sputter-cleaned samples. In all cases three types of spectra are shown: (i) sample capped in situ before venting and transport to the XPS instrument, characteristic of a native surface, (ii) uncapped sample in the as received state, (iii) uncapped samples after relatively gentle ion etch with $0.5 \mathrm{keV} \mathrm{Ar}^{+}$ions incident at the angle of $70^{\circ}$ from the surface normal.

\subsubsection{AlN and SiN}

$\mathrm{Al} 2 \mathrm{p}$ and $\mathrm{Al} 2$ s core level peaks from polycrystalline AlN films capped with a $25 \AA$ thick Cr layer are situated at 74.11 and $119.07 \mathrm{eV}$, respectively. A detailed comparison of the $\mathrm{Al}$ 2s spectra from Cr-capped and uncapped $\mathrm{Ar}^{+}$-etched films (not shown) indicated that spectra are identical with no apparent signs of ion damage in the latter case. ${ }^{37}$

The Si 2p peak from SiN capped with a 25A-thick Cr layer was detected at $102.11 \mathrm{eV}$ (not shown). Comparison to the corresponding signal obtained from the uncapped $\mathrm{Ar}^{+}$-etched SiN film reveals that the sputter-cleaned sample has somewhat higher full-width-athalf-maximum (FWHM), 1.79 vs $1.74 \mathrm{eV}$, which may be a signature of some ion damage or artefact resulting from the use of low-energy electron charge compensation in the latter case.

\subsubsection{First row TM nitrides (TiN, VN, and CrN)}

The Ti $2 p$ spectrum of TiN is by far the most frequently reported core level spectrum of all group IVb-VIb TM nitrides. This dominance is due to the nitride's wide application range, but also the peculiar satellite peaks that appear on the high BE side of main lines have attracted much scientific attention. As shown in Fig. 4(a) the Ti $2 p$ spin-orbit split 2p $3 / 2$ and 2p $1 / 2$ components from TiN are present at 454.95 and $460.89 \mathrm{eV}$, respectively, while the satellite features (marked with "S”), best visible in the spectra acquired from films capped with a $23 \AA$ thick Cr layer, are shifted by $3.1 \mathrm{eV}$ towards higher BE with respect to the primary 
peaks. As a consequence, satisfactory fit of the Ti 2p spectrum from native TiN surface (see Fig. 6(a)) requires two pairs of peaks: (i) asymmetric functions for the main components, which is explained by energy losses due to simultaneous excitations of valence electrons, as the density of states near and at the Fermi level is high, and (ii) Voigt functions with 95\% Lorentzian ingredient for satellite peaks. Satellite peaks are also observed in higher-order nitrides of Ti, like TiAlN (Ref.38) or TiSiN. ${ }^{39}$

The origin of satellite peaks is widely discussed in the literature, starting with the first report by Ramqvist et al., ${ }^{40}$ where the assignment to titanium oxide was proposed as residual oxygen contamination could not be avoided. This interpretation can be rationalized by the fact that $\mathrm{BE}$ of satellite overlaps with that of $\mathrm{TiO}_{2}$ (see spectra of uncapped TiN presented in Fig. 4(a) for reference). Indeed, $\mathrm{TiO}_{x} \mathrm{~N}_{y}$ was claimed to account for the extra peaks in the Ti $2 \mathrm{p}$ spectra of sputter-cleaned TiN films in one of the early papers. ${ }^{41}$ Burrow et al. ${ }^{42}$ concluded, however, that the intensity of these extra peaks does not scale with the bulk O/Ti ratios. Later, the Ti 2p spectra gained much more attention, as it became clear that the satellites are present even in the in situ grown single-crystal TiN under extremely clean conditions and with literally no oxygen present. ${ }^{43}$ Among possible explanations, shake-up effects due to intraband transitions between filled and partially filled valence electron energy levels near the Fermi energy were proposed by Strydom et al. ${ }^{44}$ Other researchers have suggested that structural effects rather than compositional effects could be responsible for the satellite structure, ${ }^{45}$ while Saha et al. ${ }^{46}$ connected the satellite to grain boundaries between $\mathrm{TiN}$ and $\mathrm{TiO}_{2}$ in oxidized $\mathrm{TiN}$. Porte et al. ${ }^{47}$ studied Ti 2p and N 1s spectra as a function of nitrogen content in TiN, and pointed out that the appearance of $\mathrm{Ti} 2 \mathrm{p}$ satellite structure for nearly stoichiometric TiN compounds $(\mathrm{N} / \mathrm{Ti}=1)$ is correlated with a decrease in the screening ability of the conduction electrons. This interpretation was strongly supported by the work of Arranz et al. ${ }^{48}$ who demonstrated by varying the Ti concentration in $\mathrm{Ti}-\mathrm{Si}-\mathrm{N}$ and $\mathrm{Ti}-\mathrm{Al}-\mathrm{N}$ a strong increase in the relative intensity 
of the Ti 2p satellite peaks with decreasing density of states (DOS) near the Fermi level. In fact, “well-screened” and “poorly-screened” XPS peaks were observed in core level spectra of rare-earth and actinide compounds already in $1980,{ }^{49}$ where clear relation between the coupling of the so-called screening levels (i.e., levels filled by electrons screening the core-hole state) to the delocalized levels of the initial state orbitals and the intensity of satellite features was demonstrated for the first time.

The fact that the satellite intensity is a strong function of $\mathrm{N}$ content, accounts for a decreased intensity of these extra peaks in the sputter-etched TiN, as $\mathrm{N}$ gets preferentially resputtered (cf. Fig. 2). This is illustrated in Fig. 4(a), where in addition to the Ti 2p spectrum of native TiN also the corresponding peaks from the sputter-etched TiN are shown. A severe loss of the satellite intensity upon relatively gentle $\mathrm{Ar}^{+}$ion bombardment $(0.5 \mathrm{keV}$ and shallow incidence angle of $70^{\circ}$ from the surface normal) is evident. As discussed in Sect. 3.2 the N/Ti ratio decreases by $\sim 20 \%$ from 0.97 for the Cr-capped TiN to 0.78 for ion-etched film, while the area ratio between satellites and the main TiN peaks assessed from the peak model presented in Fig. 6(a) decreases by $28 \%$ when going from capped to the ion-etched sample. The $\mathrm{N}$ loss upon sputtering is directly inferred from the set of corresponding $\mathrm{N} 1$ s spectra shown in Fig. 5(a). Signals acquired from the Cr-capped TiN and from the sputter-etched samples are essentially identical in shape, with the main sharp $(F W H M=0.78 \mathrm{eV})$ peak at $397.21 \mathrm{eV}$, however, the intensity in the latter case is significantly lower. Both spectra give no indication of a $\mathrm{TiO}_{x} \mathrm{~N}_{y}$ component, which is present in the spectrum of the as-received uncapped sample at $396.12 \mathrm{eV}$.

The satellite peaks are also observed in the V 2p spectrum from VN films capped with

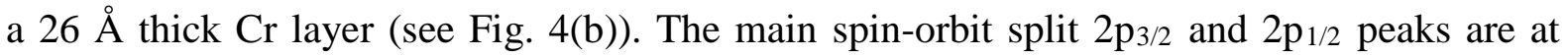
513.24 and $520.84 \mathrm{eV}$, respectively, while the satellites are shifted by $2.90 \mathrm{eV}$ to the high $\mathrm{BE}$ side of the main lines. The intensity of satellite features is clearly lower than in the TiN case, 
which may be due to the apparent $\mathrm{N}$ substoichiometry (see Tab. 1 and discussion below), and for the sputter-etched VN films they are hardly visible due to the severe $\mathrm{N}$ loss upon sputtering (see Sect. 3.2). V 2p satellites were first reported by Indlekofer et al. ${ }^{50}$ for the in situ UHV mechanically cleaned oxygen-free $\mathrm{VN}$ and $\mathrm{VN}_{0.72}$ surfaces and interpreted as originating from the well-screened and poorly screened core hole states. The authors also concluded that the screening becomes poorer as the vacancy concentration decreases resulting in higher satellites intensity for stoichiometric compounds. More recently the presence of satellite peaks was also claimed in the V 2p spectra obtained from VN surfaces sputtered with $3 \mathrm{keV} \mathrm{Ar}^{+}$ions. ${ }^{51}$ In this case, however, the satellites were not directly observed, instead, their presence was inferred based on the peak modelling. The corresponding $\mathrm{N}$ 1s spectra acquired from VN films (not shown) was dominated by a single peak at $397.22 \mathrm{eV}$ and exhibits a pronounced loss of intensity upon $\mathrm{Ar}^{+}$ion etch, with respect to the capped sample, while the shape of the spectrum remained unchanged, just as is the case for TiN.

In contrast to the two previous TMNs, the Cr 2p spectra of CrN shown in Fig. 4(c) exhibits no satellites, in agreement with previous reports on the in situ grown $\mathrm{CrN}$ films. ${ }^{52,53}$ Following the interpretation of satellite features in terms of "well-screened" and "poorly screened” peaks ${ }^{47,48}$ the lack of satellites can be correlated to a significantly higher DOS at the FE as compared to TiN and VN. The $2 \mathrm{p}_{3 / 2}$ and $2 \mathrm{p}_{1 / 2}$ peaks from a CrN sample capped with a $40 \AA$ thick W layer are at 574.92 and $584.76 \mathrm{eV}$, respectively. The effect of ion damage in the case of $\mathrm{Ar}^{+}$-etched samples is manifested by a slightly increased width of the $\mathrm{Cr} 2 \mathrm{p}_{3 / 2}$ component, as well as a $0.20 \mathrm{eV}$ shift towards lower BE (i.e., towards metal position). The higher background on the high BE side of the Cr 2p spectrum from the capped sample is due to the neighboring $\mathrm{W}$ 4s level. The $\mathrm{N}$ 1s spectrum recorded from W-capped CrN films shown in Fig. 5(b) provides evidence for a rather broad peak presumably composed of two contributions, as indicated by the asymmetry to the higher BE side of the main line centered at 
$396.92 \mathrm{eV}$, in agreement with the $\mathrm{N}$ 1s spectrum from the in situ grown $\mathrm{CrN}$ films. ${ }^{52}$ The overall shape of the $\mathrm{N}$ 1s spectra is preserved after sputter-cleaning, while the intensity relative to the corresponding metal peak decreases.

\subsubsection{Second row TMNs ( $\mathrm{ZrN}, \mathrm{NbN}$, and $\mathrm{MoN})$}

First glance at the core level spectra of the second row TMNs shown in Figs.4(d)-(f) indicates that changes induced by the $0.5 \mathrm{keV} \mathrm{Ar}^{+}$ion etch are more extensive than in the case of the first row TMNs discussed above, which is intuitively expected due to the larger mass difference between constituent atoms.

The Zr 3d spectrum from a ZrN film capped with a $26 \AA$ thick Cr layer is shown in Fig. 4(d) together with the corresponding spectrum acquired from the uncapped films before and after $\mathrm{Ar}^{+}$ion etch. The $3 \mathrm{~d}_{5 / 2}-3 \mathrm{~d}_{3 / 2}$ spin-split doublet peaks in the former spectrum are present at 179.97 and $182.40 \mathrm{eV}$. The little hump at around $185 \mathrm{eV}$ is a signature of satellites of the same nature as those observed in the $2 \mathrm{p}$ levels of $\mathrm{TiN}$ and $\mathrm{VN}$, with the lower $\mathrm{BE}$ satellite feature overlapping with the $3 \mathrm{~d}_{3 / 2}$ primary peak. For clarity, a complete peak model including satellites is presented in Fig. 6(b), where also a correct $3 d_{5 / 2} / 3 d_{3 / 2}$ peak ratio of $3: 2$ is reproduced, with the satellites shifted by $2.50 \mathrm{eV}$ towards higher $\mathrm{BE}$ with respect to the main lines. To the best of our knowledge this is the first report on satellites in the $\mathrm{Zr}$ 3d spectrum of $\mathrm{ZrN}$, although a similar signature, not addressed by the authors, was present in a reported spectrum from $\mathrm{ZrN}$ layers prepared by in situ annealing of $\mathrm{Zr}$ films in an $\mathrm{NH}_{3}$ atmosphere. ${ }^{54}$ The ion damage in the $\mathrm{Zr} 3 \mathrm{~d}$ spectrum of the sputter-etched sample is clearly seen as (i) a complete disappearance of the satellites, and (ii) broadening of the primary peaks towards the lower BE side, best observed for the $3 \mathrm{~d}_{5 / 2}$ peak (as indicated with an arrow in Fig. $4(\mathrm{~d})$ ). The latter effect indicates a presence of a reduced (N-deficient phase) component, with BE lower than that of a stoichiometric nitride, in accordance with the quantitative analyses that reveal 
severe ( 42\%) N loss upon sputtering (Sect. 3.2 and Fig. 2). These observations are fully consistent with the evolution of the corresponding $\mathrm{N}$ 1s spectra (Fig. 5(c)), which for the Crcapped $\mathrm{ZrN}$ film consists of a single peak at $397.31 \mathrm{eV}$. $\mathrm{Ar}^{+}$bombardment apart from the apparent decrease in the overall intensity, leads to the pronounced broadening on the low $\mathrm{BE}$ side of the main $\mathrm{N}$ 1s peak which is consistent with similar changes in the corresponding $\mathrm{Zr} 3 \mathrm{~d}$ spectrum.

The creation of a nitride-deficient surface layer upon $\mathrm{Ar}^{+}$-ion etch is more pronounced in the case of NbN films (see Fig. 4(e)). Nb 3d spectrum acquired from layers protected with a $25 \AA \AA$-thick Cr cap consists of a single pair of spin-split components with $3 d_{5 / 2}$ and $3 d_{3 / 2}$ peaks at 203.99 and $206.77 \mathrm{eV}$. In contrast, corresponding spectrum obtained from the $\mathrm{Ar}^{+}$-etched NbN surfaces gives clear evidence for an additional pair of peaks (indicated with arrows in Fig. 4(e)) shifted by $0.70 \mathrm{eV}$ to the lower BE with respect to the primary peaks. We attribute these features to the substoichiometric nitride layer resulting from preferential resputtering of lighter $\mathrm{N}$ atoms. The latter effects become more severe with increasing the metal atom mass, which leads to an increasing systematic error in the reported BE values obtained from ion-etched TMNs surfaces. In the case of NbN thin films, literature data are very limited, nevertheless, Havey et al. ${ }^{55}$ reported the $\mathrm{Nb} 3 \mathrm{~d}_{5 / 2}$ peak of the sputter-cleaned films at $203.20 \mathrm{eV}$, which is significantly lower than $203.99 \mathrm{eV}$ obtained here for the Cr-capped NbN, and coincides with the position of the substochiometric features in Fig. $4(\mathrm{e})$. In the same work the $\mathrm{Nb} 3 \mathrm{~d}_{5 / 2}$ peak from as grown films is reported at $203.97 \mathrm{eV}$, which agrees reasonably well with our results. In a similar way, also BE values obtained from bulk NbN samples are systematically lower, with the $\mathrm{Nb} 3 \mathrm{~d}_{5 / 2}$ peak in the range $203.40-203.85 \mathrm{eV} .{ }^{56,57}$ Prieto et al. ${ }^{58}$ reported the $\mathrm{Nb} 3 \mathrm{~d}_{5 / 2}$ peak at $204.31 \mathrm{eV}$ for stoichiometric $\mathrm{NbN}$ films grown in situ by $\mathrm{N}_{2}{ }^{+}$ion implantation and at 202.70 eV following the $3.3 \mathrm{keV} \mathrm{Ar}^{+}$etch, which resulted in an essentially metallic $\mathrm{NbN}_{x}$ layer at the very surface with $x=0.15$ (as determined by angle-resolved XPS). The satisfactory fit 
of the $\mathrm{Nb} 3 \mathrm{~d}$ spectrum of capped $\mathrm{NbN}$ sample, with a correctly-reproduced 3:2 peak ratio, requires low-intensity satellites peaks shifted by $1.80 \mathrm{eV}$ towards higher $\mathrm{BE}$ to be present. Due to low intensities involved these features are not explicit, in contrast to $\mathrm{Ti} 2 \mathrm{p}, \mathrm{V} 2 \mathrm{p}$ or $\mathrm{Zr} 3 \mathrm{~d}$ spectra discussed above. $\mathrm{N}$ 1s spectra recorded from NbN surfaces (not shown) exhibit a single narrow $(\mathrm{FWHM}=0.95 \mathrm{eV})$ peak at $397.56 \mathrm{eV}$ that loses its intensity in the spectrum recorded from the $\mathrm{Ar}^{+}$-etched sample.

Destructive effects of $\mathrm{Ar}^{+}$ion etch are also observed in the Mo $3 \mathrm{~d}$ spectra of $\mathrm{Mo}_{2} \mathrm{~N}$ films, as shown in Fig. 4(f). The capping layer in this case is a $40 \AA$-thick W film. The spectrum obtained from the capped sample, thus representative of a native $\mathrm{Mo}_{2} \mathrm{~N}$ surface, is composed of a single pair of $3 \mathrm{~d}_{5 / 2}-3 \mathrm{~d}_{3 / 2}$ peaks at 228.42 and $231.59 \mathrm{eV}$, respectively. The raising background on the high $\mathrm{BE}$ side of the spectrum is due to the neighboring $\mathrm{W} 4 \mathrm{~d}_{5 / 2}$ peak from the capping layer. A distinctly different Mo 3d signal is obtained after gentle $\mathrm{Ar}^{+}$ion etch of the uncapped $\mathrm{Mo}_{2} \mathrm{~N}$ films. An asymmetrical broadening is observed on the low BE side of the original peaks indicating the presence of a new pair of peaks due to the N-deficient surface layer. Peak fitting indicates that these new peaks are shifted by $0.50 \mathrm{eV}$ towards lower BE, i.e., to the position corresponding to the metallic Mo. ${ }^{57}$ This peak-shift is in agreement with the results of Shen who reported Mo $3 \mathrm{~d}_{5 / 2}$ peak from as grown magnetron sputtered $\mathrm{Mo}_{2} \mathrm{~N}$ films at $228.5 \mathrm{eV}$, which shifts to $228.0 \mathrm{eV}$ after surface cleaning with $3 \mathrm{keV} \mathrm{Ar}^{+}$ions. ${ }^{59}$ The latter treatment, given much higher ion energy than used in our experiments, most likely resulted in a complete reduction of the $\mathrm{Mo}_{2} \mathrm{~N}$ surface layer.

For the untreated $\mathrm{Mo}_{2} \mathrm{~N}$ crystallite surfaces, the Mo $3 \mathrm{~d}_{5 / 2} \mathrm{BE}$ of 228.4-228.5 eV was measured, ${ }^{60}$ which agrees very well with our results obtained from capped $\mathrm{Mo}_{2} \mathrm{~N}$ films. No satellite peaks are required for a good fit of the Mo 3d spectrum from the W-capped films, and the 3:2 ratio is well-reproduced with a single pair of Gaussian-Lorentzian functions. The $\mathrm{N} 1 \mathrm{~s}$ spectra obtained from W-capped, as well as from uncapped $\mathrm{Mo}_{2} \mathrm{~N}$ layers before and after 
sputter-etch are shown in Fig. 5(d). While the $\mathrm{N}$ 1s overlap with the Mo 3p $3 / 2$ metal peak is in general considered unfortunate, in these particular cases it is actually beneficial as it directly illustrates the $\mathrm{N}$ loss taking place upon $\mathrm{Ar}^{+}$sputter-cleaning. The peak fitting model constructed in order to obtain a precise estimate of the $\mathrm{N}$ 1s area and position, indicates $45 \%$ decrease in the $\mathrm{N}$ content while comparing the spectrum from capped $\mathrm{Mo}_{2} \mathrm{~N}$ surface to that after the ion etch. The extracted $\mathrm{N}$ 1s peak position is at $397.79 \mathrm{eV}$.

The here-revealed systematic error in the reported BE values of heavier TM nitrides obtained from ion-etched surfaces is not so evident in the early papers, as subtle core level shifts (or even shoulders like in Figs. 4(d)-(f)) of metal XPS signals due to $\mathrm{N}$ reduction following sputter cleaning are often obscured by a poor energy resolution and/or the use of non-monochromatized $x$-rays.

\subsubsection{Third row TMNs (HfN, TaN, and WN)}

Destructive effects of the $\mathrm{Ar}^{+}$-ion bombardment prior to XPS analyses illustrated above are even more apparent for the third row TMN's.

Figure 4(g) shows the Hf 4f spectrum from HfN films capped with a $20 \AA$-thick $\mathrm{Cr}$ layer, as well as, from the uncapped films prior and after the $\mathrm{Ar}^{+}$sputter-etch. The spin-split $4 \mathrm{f}_{7 / 2}-4 \mathrm{f}_{5 / 2}$ doublet peaks in the Cr-capped spectrum characteristic of a native HfN surface are at 15.73 and $17.38 \mathrm{eV}$, respectively. A shoulder on the high $\mathrm{BE}$ side of the $4 \mathrm{f}_{5 / 2}$ peak together with the fact that the $4 f_{5 / 2}$ component is more intense than the $4 f_{7 / 2}$ peak indicate the presence of a satellite doublet shifted to higher BE with respect to main peaks by $1.28 \mathrm{eV}$. The detailed peak model shown in Fig. $6(\mathrm{c})$, yields the $4 \mathrm{f}_{7 / 2} / 4 \mathrm{f}_{5 / 2}$ area ratio of 1.33 , as expected from quantum mechanics, and the BE splitting of doublet peaks $\Delta \mathrm{BE}=1.72 \mathrm{eV}$ (same for both sets of peaks). A very similar shoulder feature to the one shown in Fig. 4(g) was also observed in the $\mathrm{Hf} 4 \mathrm{f}$ spectrum obtained from the in situ grown single-crystal $\mathrm{NaCl}$-structure HfN film, ${ }^{61}$ 
however, no interpretation was presented. The apparent $4 \mathrm{f}_{7 / 2} / 4 \mathrm{f}_{5 / 2}$ ratio lower than unity has been previously reported for in situ mechanically cleaned HfN films, ${ }^{62}$ and attributed to the overlap with the $\mathrm{N} 2$ s peak expected at $\sim 17.5 \mathrm{eV}$. This interpretation, however, does not take into account the fact that with $\mathrm{Al} \mathrm{K \alpha}$ photons the photoionization cross section for the $\mathrm{Hf} 4 \mathrm{f}$ electrons is two orders of magnitude higher than that of N 2s. ${ }^{63}$ Similar to changes observed in 3d levels for the second row TMNs, bombardment with $\mathrm{Ar}^{+}$leads to a loss of satellite peaks and the broadening of the primary lines on the low BE side, indicative of the $\mathrm{N}$-deficient $\mathrm{HfN}_{x}$ surface layer. The resulting spectrum (Fig. 4(g)) is thus a superposition of two doublets: one due to the deeper-lying unaffected HfN layer and one due to the substoichiometric nitride at the surface. It has to be kept in mind though, that due to the high kinetic energy of Hf $4 \mathrm{f}$ electrons the XPS probing depth is somewhat longer than in the case of 3d levels (and even more so for $2 p$ levels), hence the contribution from the unaffected TMN layer is more

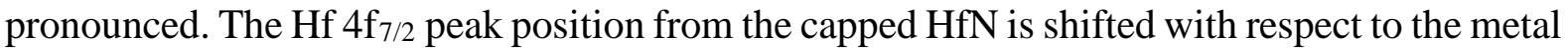
peak by $1.50 \mathrm{eV}$, and is significantly higher than $14.80 \mathrm{eV}$ reported for magnetron sputtered HfN films. ${ }^{64}$ Since in the latter case, where films were sputter-cleaned prior to analyses, it appears that the reported low BE is due to the N-deficient layer being measured. This conclusion is supported by the fact that the BE of the $4 \mathrm{f}_{7 / 2}$ peak obtained from HfN layers grown in situ by nitrogen implantation is $15.6 \mathrm{eV},{ }^{65}$ which corresponds very well to $15.73 \mathrm{eV}$ measured for the Cr-capped HfN film. Severe changes observed in the Hf $4 \mathrm{f}$ core level spectra recorded from Cr-capped and $\mathrm{Ar}^{+}$-etched films are also reflected in the corresponding $\mathrm{N} 1 \mathrm{~s}$ signals shown in Fig. 5(e). In the former case, the $\mathrm{N}$ 1s spectrum is dominated by a single relatively broad peak $(\mathrm{FWHM}=1.65 \mathrm{eV})$ at $397.19 \mathrm{eV}$, which loses ca. $50 \%$ of the intensity upon surface ion cleaning and exhibits more complex structure with multiple components due to the formation of substoichiometric nitride at the surface. 
The Ta 4f spectrum from TaN films capped with a $27 \AA$-thick W layer are shown in Fig. 4(h) together with signals acquired from uncapped layers before and after $\mathrm{Ar}^{+}$-sputter etch. The $4 f_{7 / 2}$ and $4 f_{5 / 2}$ peaks of native TaN surface are at 23.89 and $25.73 \mathrm{eV}$, respectively. The little peak at $\sim 22.5 \mathrm{eV}$ is assigned to $\mathrm{O} 2 \mathrm{~s}$ (Ref. 57) due to high oxygen content in the capping layer. Clearly, upon sputter-cleaning with $0.5 \mathrm{keV} \mathrm{Ar}^{+}$another pair of Ta $4 \mathrm{f}$ peaks appears in the spectrum, shifted with respect to the original peaks to lower BE by approximately $1 \mathrm{eV}$, with the $4 \mathrm{f}_{7 / 2}$ component at $22.82 \mathrm{eV}$ as indicated by modelling. Such low BE is indicative of the hexagonal $\mathrm{Ta}_{2} \mathrm{~N}$ phase, for which Prieto et al. reported the $\mathrm{Ta} 4 \mathrm{f}_{7 / 2}$ peak at $22.85 \mathrm{eV}{ }^{66}$ Signal intensity of the $\mathrm{Ta}_{2} \mathrm{~N}$ peaks is comparable to that from the unaffected TaN (present at the same $\mathrm{BE}$ as in the Ta $4 \mathrm{f}$ spectrum recorded from capped samples) indicating that the effects from ion bombardment artefacts are even more severe than for HfN, in agreement with the TRIM- simulated nitrogen-to-metal sputter yield ratios (see Tab.1).

Well-resolved new components in the Ta 4f spectrum of W-capped TaN films together with revealed chemical identity of the new phase formed upon $\mathrm{Ar}^{+}$-ion etch allow for the estimation of the $\mathrm{Ta}_{2} \mathrm{~N}$ thickness $d$ based on the relative signal intensities in the Ta $4 \mathrm{f}$ spectra using $^{67,68}$

$$
d=\lambda_{B} \ln \left(\frac{N_{A} \lambda_{A} I_{B}}{N_{B} \lambda_{B} I_{A}}+1\right)
$$

in which $\lambda$ is the inelastic electron mean free path, $N$ is the volume density of Ta atoms, and $I$ is the measured XPS peak intensity. Here, indices $A$ and $B$ refer to the original TaN film and the ion beam modified layer $\left(\mathrm{Ta}_{2} \mathrm{~N}\right)$, respectively. For simplicity, we use $\lambda_{A}=\lambda_{B}=19.7 \AA$ for Ta 4f electrons in Ta excited with $\mathrm{Al} \mathrm{K}_{\alpha} x$-rays. ${ }^{19}$ Under these assumptions $d=12 \AA$. This can be compared to the effective depth of collision cascade events induced by $0.5 \mathrm{keV} \mathrm{Ar}^{+}$ions incident at an angle of $70^{\circ}$ from the surface normal, which can be estimated from TRIM simulations of ion/surface interactions, and corresponds to the average TaN primary recoil 
projected range $\xi$ accounting for straggle. For Ta and $\mathrm{N}$ recoils, $\xi_{T a}=14 \AA$ and $\xi_{N}=12 \AA$, which agrees very well with the XPS estimates above.

Literature results very consistently support our interpretation of data presented in Fig. 4(h). The Ta $4 \mathrm{f}_{7 / 2}$ peak from the in situ grown TaN films by low energy $\mathrm{N}$ implantation is found at $23.8-23.9 \mathrm{eV},{ }^{69}$ in excellent agreement to $23.89 \mathrm{eV}$ obtained here for capped TaN, while significantly lower values, from 23.2 to $23.5 \mathrm{eV}$, are reported for layers exposed to $\mathrm{Ar}^{+}$etch prior to XPS analyses. ${ }^{70,71}$ Peak modelling gives no clear evidence for satellites in the case of the Ta $4 \mathrm{f}$ spectrum. The $\mathrm{N}$ 1s spectra of $\mathrm{W}$-capped TaN films along with those from uncapped samples in the as-received states and after sputter-etch are shown in Fig. 5(f). Similar to the N 1s spectrum of $\mathrm{Mo}_{2} \mathrm{~N}$, also in this case there is a partial overlap with metal signal (Ta $4 \mathrm{p}_{3 / 2}$ ), which is very useful in illustrating the severe reduction in $\mathrm{N}$ content caused by gentle $\mathrm{Ar}^{+}$-ion etch. The peak modelling revels that the $\mathrm{N}$ 1s peak characteristic of a native TaN surface is centered at $397.54 \mathrm{eV}$, and loses $46 \%$ of its intensity upon ion bombardment.

$\mathrm{W} 4 \mathrm{f}$ core levels from $\mathrm{W}$-capped $\mathrm{W}_{2} \mathrm{~N}$ films are not discussed here because of signal overlap from the capping layers, as the nitride peaks are shifted from the metal positions by not more than $0.6 \mathrm{eV} .^{57,72}$ Very low heat of formation of WN makes it useful as a cap on other TMN films, at the same time presents a challenge to find a proper capping material that would not form a nitride upon deposition onto $\mathrm{W}_{2} \mathrm{~N}$. The $\mathrm{N} 1$ s signal recorded from $\mathrm{W}_{2} \mathrm{~N}$ films capped with W (not shown) consisted of a single peak centered at $397.94 \mathrm{eV}$.

\section{$3.6 N$ 1s core-level binding energies}

Figure 7 presents the $\mathrm{N}$ 1s $\mathrm{BE}$ values obtained from capped TMN films, thus characteristic of a native surface, and referenced according to the ISO standards, as described in Sect. 3.3. In addition, the range of reported BE values is indicated for each materials system with a grey stripe. 
Clearly, published N 1s BE:s have large spread, typically of the order of $1 \mathrm{eV}$ (with the exception of VN, which may be due to the very few publications available). Several factors are responsible for this situation including (i) state of the surface after commonly applied sputter cleaning (reduced $\mathrm{N}$ content, depending on the $\mathrm{Ar}^{+}$energy/incidence angle), (ii) $\mathrm{BE}$ reference used, (iii) surface charging state, and (iv) non-confirmed sample stoichiometry and phase content (different materials being compared). Often film stoichiometry is assessed based on the XPS peak areas following the $\mathrm{Ar}^{+}$etch, which as discussed in Sect.3.2, leads to grossly underestimated $\mathrm{N}$ content, and $\mathrm{N}$ signal not necessarily representative of the as grown film (cf. Sect. 3.5).

In the case of data obtained from TMN films with capping layers, thus representative of native as-grown film surfaces, uncertainties associated with issues (i)-(iv) above are eliminated; film stoichiometry and crystallinity are thoroughly characterized by bulk-probing techniques (cf. Tab. 1), all spectra are acquired under exactly the same experimental conditions and referenced in a consistent way, while avoiding spectra-deteriorating effects of $\mathrm{Ar}^{+}$ion etch. This allows for the first reliable comparison of TMN N 1s BE:s, which reveals interesting trends. For the first row TMNs, TiN and VN, N 1s peak is centered at $397.21 \mathrm{eV}$, while lower $\mathrm{BE}$ is measured in the case of $\mathrm{CrN}(396.92 \mathrm{eV})$. Interestingly, for the second row TMNs, $\mathrm{N} 1 \mathrm{~s}$ BE increases with increasing metal mass, from $397.31 \mathrm{eV}$ with $\mathrm{ZrN}$ to $397.79 \mathrm{eV}$ for MoN. A similar trend is observed in the case of the third row TMNs, with N 1s BE varying from 397.19 $\mathrm{eV}$ for $\mathrm{HfN}$ to $397.94 \mathrm{eV}$ for $\mathrm{WN}$. Thus, for the second and the third row TMN N 1s BE is essentially determined by the metal atom group placement in the periodic table. $\mathrm{N}$ 1s $\mathrm{BE}$ in AlN is $397.21 \mathrm{eV}$, i.e., essentially identical to that measured for $\mathrm{TiN}$ and $\mathrm{VN}$, while significantly higher value of $397.87 \mathrm{eV}$ is obtained from Cr-capped SiN surfaces.

Since the measured BE is a difference between the total energy of the final state (i.e., with a core hole created upon photoionization) and the total energy of the initial state (prior to 
ionization), ${ }^{73}$ core level BE shifts may result from both final and initial state contributions. ${ }^{74}$ Common examples of the former effects include relaxation phenomena, while the most recognized example of the initial state contribution is the chemical shift, where the valence charge density on an atom prior to the photoionization event has a direct effect on the energy necessary to create the positive ion.

Assuming for a moment that BE shifts summarized in Fig. 7 are solely reflecting differences in the initial state, one can observe that from $\mathrm{ZrN}$ to MoN (and from HfN to WN) the valence charge density on the $\mathrm{N}$ atoms decreases, indicative of a less ionic (hence more covalent) bonding character. This is associated with an overall increase in the valence charge density at the Fermi level due to the gradual filling of the $d$-type orbitals and simultaneous decrease of the $\mathrm{N}$-metal bonding distance reflected by decreasing relaxed lattice parameter: from 4.62 to $4.24 \AA$ and from 4.56 to $4.24 \AA$ for the $2^{\text {nd }}$ and the $3^{\text {rd }}$ row TMNs, respectively (cf. Tab.1). Why the corresponding trend is not observed for the first row TMN, with particularly lowered N 1s BE of CrN, is proposed for future research.

\section{Conclusions}

We present a first consistent set of artefact-free XPS core level spectra with extracted binding energies for group IVb-VIb transition metal nitride thin films including TiN, VN, CrN, ZrN, NbN, MoN, HfN, TaN, and WN as well as the common components in multinary alloy systems AlN and SiN. XPS spectra are acquired from surfaces that are either (i) subject to gentle ion-etch with $0.5 \mathrm{eV} \mathrm{Ar}^{+}$to remove surface oxides resulting from the $\sim 2$-min-long air exposure during sample transfer to the XPS instrument, or (ii) in situ capped with a few nm thick $\mathrm{Cr}$ or $\mathrm{W}$ layers in the deposition system prior to air-exposure, thus characteristic of a virgin TMN surface.

Thanks to an excellent energy resolution of the instrument used, a direct comparison of two types of core-level spectra reveals that even very mild etching conditions result in a severe loss 
of nitrogen (20-45\%, depending on materials system) and creation of a N-depleted surface layer that affects the appearance of core-level spectra and, hence, extracted BE values, by as much as $1.07 \mathrm{eV}$. A review of the available literature results shows that BE:s from sputter-etched surfaces are often not representative of a native nitride surface, but rather substoichiometric, $\mathrm{N}$-deficient surface layer. These bond-modifying effects of $\mathrm{Ar}^{+}$-ion bombardment increase with increasing the metal atom mass, as the nitrogen-to-metal sputter yield ratio also increases, rendering them unreliable.

The superior quality of the XPS spectra obtained from capped TMN films in a nondestructive way is made evident. In agreement with the previously published spectra from in situ grown and analyzed layers, numerous metal peaks, including Ti 2p, V 2p, Zr 3d, and Hf 4f, exhibit pronounced satellite features, that are very sensitive to the $\mathrm{Ar}^{+}$-ion bombardment, and therefore of lower intensity or even completely missing in the spectra from corresponding ion-etched TMN's surfaces. The XPS-determined N/metal ratios are 25-90\% higher than those from ion-cleaned samples, and in majority of cases agree well with the bulk values obtained with RBS and ToF-E ERDA analyses. The N 1s BE's extracted from spectra acquired on capped TMN films show a systematic trend with increasing metal atomic number, which contrasts with a large spread of previously reported "reference" BE values. For the second and the third row TMN, N 1s BE is found to be sensitively determined by the metal atom group placement in the periodic table.

Thus, non-destructive XPS by ultra-thin (nm) capping-layer technique provides an opportunity to obtain high-quality spectra, characteristic of the in situ grown and analyzed films and allows for extracting core level BE values that are more reliable than those obtained from sputter-cleaned N-deficient surfaces. Results presented here, obtained from a broad and consistent set of binary TMN grown and analyzed under the same conditions and in the same ISO-calibrated instrument, provide a useful reference for future XPS studies of multinary 
TMN's allowing for more reliable deconvolution of complex core level spectra.

\section{Acknowledgements}

We acknowledge support from the VINN Excellence Center Functional Nanoscale Materials (FunMat) Grant 2005-02666, the Swedish Government Strategic Research Area in Materials Science on Functional Materials at Linköping University (SFO-Mat-LiU 2009-00971), and the Knut and Alice Wallenberg Foundation Scholar Grant 2011.0143. Daniel Primetzhofer acknowledges a research infrastructure fellowship of the Swedish Foundation for Strategic Research (SSF) under contract RIF14-0053. We thank Konstantinos Bakoglidis for help with AFM measurements. 


\section{Table captions}

Tab. 1 Crystalline phases, lattice parameters $a_{o}$, preferred out-of-plane orientation (PO), rootmean-square (RMS) surface roughness, heat of nitride formation $\Delta_{f} H_{T M N}^{0}$, capping layer material and thickness, TRIM simulated sputter yield ratio $\gamma_{N} / \gamma_{T M}$ for $0.5 \mathrm{keV} \mathrm{Ar}^{+}$ions incident at $70^{\circ}$ from the surface normal, bulk N/metal ratios derived from ToF-E ERDA and RBS (only when deviation from unity is statistically significant), XPS-derived N/metal ratios from the in situ capped and uncapped sputter-cleaned TMN surfaces, as well as minor (contaminant) elements as detected by ToF-E ERDA analyses of TMN films grown at $470{ }^{\circ} \mathrm{C}$ on $\mathrm{Si}(001)$ substrates.

Tab. 2 Binding energy values extracted from $\mathrm{N}$ 1s and primary metal core level spectra recorded from the in situ capped TMN films grown at $470{ }^{\circ} \mathrm{C}$ on $\mathrm{Si}(001)$ substrates.

\section{Figure captions}

Fig. 1. Bright-field cross-sectional TEM and HR-TEM images together with a corresponding SAED patterns obtained from single-phase cubic NbN films. The HR-TEM image is acquired in the upper-most portion of the film.

Fig. 2. XPS-derived N/metal ratios obtained from in situ capped TMN films as well as from uncapped layers sputter-cleaned with $0.5 \mathrm{keV} \mathrm{Ar}^{+}$ions incident at $70^{\circ}$ from surface normal. For reference, bulk values obtained from ToF-ERDA and RBS analyses are also included.

Fig. 3. XPS-derived N/Cr ratios for the in situ capped $\mathrm{CrN}$ films grown at $470{ }^{\circ} \mathrm{C}$ on $\mathrm{Si}(001)$ substrates as a function of sputtering time. 
Fig. 4. The main metal core level spectra for (a) TiN, (b) VN, (c) CrN, (d) $\mathrm{ZrN}$, (e) NbN, (f) $\mathrm{Mo}_{2} \mathrm{~N}$, (g) HfN, and (f) TaN films grown at $470{ }^{\circ} \mathrm{C}$ on $\mathrm{Si}(001)$ substrates. For each TMN three surfaces are analyzed: (i) sample capped in situ before venting and transport to the XPS instrument, characteristic of a native surface, (ii) uncapped sample in the as received state, and

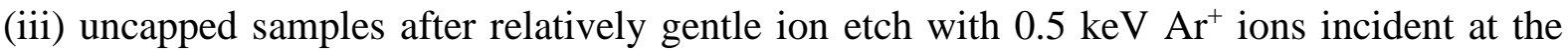
angle of $70^{\circ}$ from surface normal. All metal lines are normalized to the intensity of the highest feature. Arrows indicate new features that appear upon $\mathrm{Ar}^{+}$ion etch.

Fig. 5. N 1s XPS spectra obtained from core level spectra for (a) TiN, (b) CrN, (c) ZrN, (d) $\mathrm{Mo}_{2} \mathrm{~N}$, (e) HfN, and (f) TaN films grown at $470{ }^{\circ} \mathrm{C}$ on $\mathrm{Si}(001)$ substrates. For each TMN, three surfaces are analyzed: (i) sample capped in situ before venting and transport to the XPS instrument, characteristic of a native surface, (ii) uncapped sample in the as received state, and (iii) uncapped samples after relatively gentle ion etch with $0.5 \mathrm{keV} \mathrm{Ar}^{+}$ions incident at the angle of $70^{\circ}$ from surface normal. $\mathrm{N}$ 1s spectra are normalized to the corresponding metal signal to facilitate direct comparison between spectra obtained from capped and sputter-cleaned samples.

Fig. 6. XPS metal core level peak models for (a) TiN, (b) ZrN, and (c) HfN films grown at 470 ${ }^{\circ} \mathrm{C}$ on $\mathrm{Si}(001)$ substrates and capped in situ before venting and transport to the XPS instrument.

Fig. 7. N 1s BE obtained from TMN samples grown at $470{ }^{\circ} \mathrm{C}$ on $\mathrm{Si}(001)$ substrates and capped in situ before venting and transport to the XPS instrument, characteristic of a native surface. Range of previously reported values is indicated with a grey line. 


\section{References}

${ }^{1}$ O. Knotek, M. Böhmer, T. Leyendecker, J. Vac. Sci. Technol. A 4 (1986) 2695

${ }^{2}$ T. Leyendecker, O. Lemmer, S. Esser, J. Ebberink, Surf. Coat. Technol. 48 (1991) 175

${ }^{3}$ J.M. Molarius, A.S. Korhonen, E. Harju, R. Lappalainen, Surf. Coat. Technol. 33 (1987) 117

${ }^{4}$ V.R. Parameswaran, J.-P. Immarigeon, D. Nagy, Surf. Coat. Technol. 52 (1992) 251

${ }^{5}$ I. Petrov, E. Mojab, F. Adibi, J.E. Greene, L. Hultman, J.-E. Sundgren, J. Vac. Sci. Technol. A 11 (1993) 11

${ }^{6}$ J.S. Chun, P. Desjardins, C. Lavoie, C.-S. Shin, C. Cabral Jr., I. Petrov, J.E. Greene, J. Appl. Phys. 89 (2001) 7841

${ }^{7}$ O. Knotek, M. Böhmer, T. Leyendecker, J. Vac. Sci. Technol. A 4 (1986) 2695

${ }^{8}$ W.-D. Münz, T. Hurkmans, G. Keiren, T. Trinh, J. Vac. Sci. Technol. A 11 (1993) 2583

${ }^{9}$ A. Kimura, H. Hasegawa, K. Yamada, T. Suzuki, Surf. Coat. Technol. 120-121 (1999) 438

${ }^{10}$ P.H. Mayrhofer, A. Hörling, L. Karlsson, J. Sjölen, T. Larsson, C. Mitterer, L. Hultman, Appl. Phys. Lett. 83 (2003) 2049

${ }^{11}$ G. Greczynski and L. Hultman, Appl. Surf. Sci. 387 (2016) 294

${ }^{12}$ For more detailed treatment see, e.g. T. Wagner, J.Y. Wang, and S. Hofmann "Sputter Depth Profiling in AES and XPS" in "Surface Analysis by Auger and X-ray Photoelectron Spectroscopy” Ed. D. Briggs and J.T. Grant, IM Publications, Manchester, 2003, p.618 and references therein

${ }^{13}$ National Institute of Standards and Technology (NIST) X-ray Photoelectron Spectroscopy Database, Version 4.1 compiled by A.V. Naumkin, A. Kraut-Vass, S.W. Gaarenstroom, and C.J. Powell, http://srdata.nist.gov/xps/ accessed on 2016-04-07

${ }^{14}$ I. Bertóti Surf. Coat. Technol. 151 -152 (2002) 194

${ }^{15}$ I. Milošev, H.-H. Strehbtow, B. Navinšek, Thin Solid Films 303 (1997) 246

${ }^{16}$ G. Greczynski, I. Petrov, J.E. Greene, and L. Hultman, J. Vac. Sci. Technol. A 33 (2015) 05E101-1

${ }^{17}$ http://www.cemecon.de/coating_technology/coating_units/hipims_sputter_coating_system/index_eng.html, accessed on 2016-06-15

${ }^{18}$ I. Petrov, P.B. Barna, L. Hultman, and J.E. Greene, J. Vac. Sci. Technol. 21, S117 (2003)

${ }^{19}$ S. Tanuma, C. J. Powell and D. R. Penn, Surf. Interf. Anal. 43 (2010) 689

${ }^{20}$ G. Greczynski, S. Mráz, L. Hultman, J.M. Schneider, Appl. Phys. Lett. 108 (2016) 041603

${ }^{21}$ Kratos Analytical Ltd.: library filename: "casaXPS_KratosAxis-F1s.lib”

${ }^{22}$ K.S. Janson, Internal Report 2004, Uppsala University, Sweden

${ }^{23}$ Y. W. Zhang, H. J. Whitlow, T.Winzell, I. F. Bubb, T. Sajavaara, K. Arstila, and J. Keinonen, Nucl. Instrum. Methods Phys. Res., B 149 (1999) 477

${ }^{24}$ G. Greczynski, J. Lu, M. Johansson, J. Jensen, I. Petrov, J.E. Greene, L. Hultman, Surf. Coat. Technol. 206 (2012) 4202

${ }^{25}$ G. Greczynski, J. Lu, J. Jensen, S. Bolz, W. Kölker, Ch. Schiffers, O. Lemmer, J.E. Greene, and L. Hultman, Surf. Coat. Technol. 257 (2014) 15

${ }^{26}$ The JCPDS database (1998), data sets: 38-1420 (TiN), 35-0768 (VN), 11-0065 (CrN), 35-0753 (ZrN),

38-1155 (NbN), 33-0592 (HfN)

${ }^{27}$ The JCPDS database (1998), data set: 25-1133 (AlN)

${ }^{28}$ The JCPDS database (1998), data sets: $25-1366\left(\mathrm{Mo}_{2} \mathrm{~N}\right)$ and 25-1367 (MoN)

${ }^{29}$ The JCPDS database (1998) data set: 32-1283 (TaN)

${ }^{30}$ The JCPDS database (1998) data set: 25-1257 $\left(\mathrm{W}_{2} \mathrm{~N}\right)$

${ }^{31}$ J. F. Ziegler, J. P, Biersack, U. Littmark, "The Stopping and Range of Ions in Solids," vol. 1 of series

"Stopping and Ranges of Ions in Matter," Pergamon Press, New York (1984).

${ }^{32}$ P. Swift, Surf. Interf. Anal. 4 (1982) 47

${ }^{33}$ T.L. Barr and S. Seal, J. Vac. Sci. Technol. A 13 (1995) 1239

${ }^{34}$ See for instance Chapter 1 in S. Hüfner "Photoelectron Spectroscopy: Principles and Applications", SpringerVerlag, Berlin, 2003.

${ }^{35}$ M.P. Seah, Surf. Interface Anal. 31 (2001) 721

${ }^{36}$ ISO 15472, "Surface chemical analysis- $x$-ray photoelectron spectrometers - calibration of energy scales" (ISO, Geneva, 2001)

${ }^{37} \mathrm{Al} 2 \mathrm{p}$ signals can not be directly compared due to the overlap with $\mathrm{Cr} 3 \mathrm{~s}$ signal in the case of capped AlN sample.

${ }^{38}$ G. Greczynski, J. Jensen, J. E. Greene, I. Petrov, and L. Hultman, Surf. Sci. Spectra 21 (2014) 35

${ }^{39}$ M. Diserens, J. Patscheider, F. Lévy, Surf. Coat. Technol. 108-109 (1998) 241

${ }^{40}$ L. Ramqvist, K. Hamrin, G. Johansson, A. Fahlman, C. Nordling, J. Phys. Chem. Solids 30 (1969) 1835

${ }^{41}$ K.S. Robinson and P.M.A. Sherwood, Surf. Interf. Anal 6 (1984) 261

${ }^{42}$ B.J. Burrow, A.E. Morgan, and R.C. Ellwanger, J. Vac. Sci. Technol. A 4 (1986) 2463 
${ }^{43}$ R.T. Haasch, T. -Y. Lee, D. Gall, J. E. Greene, and I. Petrov, Surface Science Spectra 7 (2000) 193

${ }^{44}$ L. R. Strydom and S. Hofmann, J. Electron Spectrosc. Relat. Phenom. 56 (1991) 85

${ }^{45}$ P. Prieto, R.E. Kirby, J. Vac. Sci. Technol. A 13 (1995) 2819

${ }^{46}$ N.C. Saha, H.G. Tompkins, J. Appl. Phys. 72 (1992) 3072

${ }^{47}$ L. Porte, L. Roux, J. Hanus, Phys. Rev. B 28 (1983) 3214

${ }^{48}$ A. Arranz, C. Palacio, Surf. Sci. 600 (2006) 2510

${ }^{49}$ J. C. Fuggle, M. Campagna, Z. Zolnierek, R. Lässer, A. Platau, Phys. Rev. Lett. 45 (1980) 1597

${ }^{50}$ G. Indlekofer, J.M. Mariot, W. Lengauer, E. Beauprez, P. Oelhafen, C.F. Hague, Solid State Commun. 72, (1989) 419

${ }^{51}$ A. Glaser, S. Surnev, F.P. Netzer, N. Fateh, G.A. Fontalvo, C. Mitterer, Surface Science 601 (2007) 1153

${ }^{52}$ C. Palacio, A. Arranz, D. Díaz, Thin Solid Films 513 (2006) 175

${ }^{53}$ R. T. Haasch, T.-Y. Lee, D. Gall, J.E. Greene, and I. Petrov, Surf. Sci. Spec. 7 (2000) 250

${ }^{54}$ P. Prieto, L. Galan, and J. M. Sanz, Phys. Rev. B 47 (1993) 1613

${ }^{55}$ K.S. Havey, J.S. Zabinski, S.D. Walck, Thin Solid Films 303 (1997) 238

${ }^{56}$ A. Darlinski and J. Halbritter, Surf. Interf. Anal. 10 (1987) 223

${ }^{57}$ J.F. Moulder,W.F. Stickle, P.E. Sobol, K.D. Bomben, "Handbook of X-ray Photoelectron Spectroscopy”, Perkin-Elmer Corporation, Eden Prairie, USA, 1992

${ }^{58}$ P. Prieto, L. Galan, and J.M. Sans, Surf. Sci. 251/252 (1991) 701

${ }^{59}$ Y.G. Shen Mat. Sci. Eng. A359 (2003) 158

${ }^{60}$ G-T. Kim, T-K. Park, H. Chung, Y-T. Kim, M-H. Kwon, J-G. Choi, Appl. Surf. Sci. 152 (1999) 35

${ }^{61}$ J. Lindstrom, L.I. Johansson, P.E.S. Persson, A. Callenas, D.S.L. Law, and A.S. Christensen, Phys. Rev. B 39 (1989) 3599

${ }^{62}$ A.J. Perry, L. Schlapbach, and W. D. Sproul, Solid State Comm. 62 (1987) 23

63 J.H. Scofield, J. Electron Spectrosc. Relat. Phenom. 8 (1976) 129

${ }^{64}$ S. Shinkai and K. Ssasaki, Jpn. J. Appl. Phys. 38 (1999) 2097

${ }^{65}$ A. Arranz, Surf. Sci. 563 (2004) 1

${ }^{66}$ P. Prieto, L. Galan and J.M. Sanz, Appl. Surf. Sci. 70/71 (1993) 186

${ }^{67}$ T. A. Carlson, Surf. Interf. Anal. 4 (1982) 125

${ }^{68}$ B.R. Strohmeier, Surf. Interf. Anal. 15 (1990) 51

${ }^{69}$ A. Arranz, and C. Palacio, Appl. Phys. A 81 (2005) 1405

${ }^{70}$ W-H. Lee, J-C. Lin, C. Lee, Mat. Chem. Phys. 68 (2001) 266

${ }^{71}$ Q.Y. Zhang, X.X. Mei, D.Z. Yang, F.X. Chen, T.C. Ma, Y.M. Wang, F.N. Teng, Nucl. Instr. Meth. Phys. Research B 127/128 (1997) 664

${ }^{72}$ M. Wen, Q.N. Meng, W.X. Yu, W.T. Zheng, S.X. Mao, M.J. Hu, Surf. Coat. Technol. 205 (2010) 1953

${ }^{73}$ W.F. Egelhoff, Surf. Sci. Rep. 6 (1987) 255

${ }^{74}$ K. Siegbahn, C. Nordling, A. Fahlman, R. Nordberg, K. Hamrin, J. Hedman, G. Johansson, T. Bergmark, S.E. Karlsson, I.. Lindgren, and B. Lindberg, "ESCA - Atomic, Molecule and Solid State Structure Studied by Means of Electrn Spectroscopy”, Almqvist \& Wiksells Boktryckeri, Uppsala, Sweden, 1967 


\begin{tabular}{|c|c|c|c|c|c|c|c|c|c|c|c|c|}
\hline TMN & $\begin{array}{l}\text { major } \\
\text { crystal } \\
\text { phase }\end{array}$ & $\begin{array}{l}a_{\circ} \\
{[\AA ̊]}\end{array}$ & $\mathrm{PO}$ & $\begin{array}{c}\text { RMS } \\
{[\AA \AA]}\end{array}$ & $\begin{array}{l}\Delta_{f} H_{T M N}^{0} \\
{[\mathrm{~kJ} / \mathrm{mol}]}\end{array}$ & $\begin{array}{l}\text { Cap } \\
{[\AA]}\end{array}$ & $\gamma_{\mathrm{N}} / \gamma_{\mathrm{TM}}$ & $\begin{array}{c}\text { N/TM } \\
\text { (ERDA) }\end{array}$ & $\begin{array}{l}\text { N/TM } \\
\text { (RBS) }\end{array}$ & $\begin{array}{l}\text { N/TM } \\
\text { (XPS) } \\
\text { cap }\end{array}$ & $\begin{array}{l}\mathrm{N} / \mathrm{TM} \\
\text { (XPS) } \\
\mathrm{Ar}^{+}- \\
\text {etch }\end{array}$ & $\begin{array}{c}\text { Minor elements } \\
\text { (ERDA) } \\
\text { [at \%] }\end{array}$ \\
\hline AIN & $h$-AIN & $3.11^{(f)}$ & 0002 & 4.5 & -318 & $\mathrm{Cr}(25)$ & 1.36 & 1.00 & 1.00 & $0.79^{(a)}$ & $0.62^{(a)}$ & $\mathrm{O}(1.3), \mathrm{H}(1.3)$ \\
\hline $\mathrm{SiN}$ & - & - & - & 1.6 & -829 & $\mathrm{Cr}(25)$ & 1.68 & 1.04 & 1.00 & 0.98 & 0.74 & $\mathrm{O}(0.5), \mathrm{C}(0.3), \mathrm{H}(1.2)$ \\
\hline $\mathrm{TiN}$ & $c-\mathrm{TiN}$ & 4.24 & 111 & 15.8 & -338 & $\mathrm{Cr}(23)$ & 1.87 & 0.98 & 0.92 & 0.97 & 0.78 & $\mathrm{O}(1.4), \mathrm{C}(1.0)$ \\
\hline VN & $c-\mathrm{VN}$ & 4.13 & 111 & 13.6 & -217 & $\operatorname{Cr}(26)$ & 2.03 & 0.83 & 0.85 & 0.83 & 0.57 & $\mathrm{O}(0.5), \mathrm{C}(0.8), \mathrm{H}(0.4)$ \\
\hline $\mathrm{CrN}$ & $c-\mathrm{CrN}$ & 4.16 & 002 & 10.1 & -117 & W (40) & 1.62 & 0.92 & 1.00 & 1.00 & 0.53 & $\mathrm{O}(0.6), \mathrm{C}(0.6), \mathrm{H}(0.4)$ \\
\hline $\mathrm{ZrN}$ & $c-\mathrm{ZrN}$ & 4.62 & 002 & 5.0 & -365 & $\mathrm{Cr}(26)$ & 2.56 & 1.04 & 1.00 & 1.11 & 0.64 & $\mathrm{O}(0.7), \mathrm{C}(1.2), \mathrm{H}(0.2), \mathrm{F}(1.4)$ \\
\hline $\mathrm{NbN}$ & $c-\mathrm{NbN}$ & 4.41 & 002 & 8.2 & -237 & $\mathrm{Cr}(25)$ & 3.03 & 1.10 & 1.13 & 0.91 & 0.55 & $\mathrm{O}(0.5), \mathrm{C}(1.4), \mathrm{H}(0.7)$ \\
\hline MoN & $c-\mathrm{Mo}_{2} \mathrm{~N}^{(\mathrm{d})}$ & 4.24 & 002 & 4.7 & -70 & W $(40)$ & 2.68 & 0.73 & 0.75 & $0.84^{(\mathrm{b})}$ & $0.46^{(b)}$ & $\mathrm{O}(0.4), \mathrm{C}(0.7), \mathrm{H}(0.5)$ \\
\hline $\mathrm{HfN}$ & $c-\mathrm{HfN}$ & 4.56 & 002 & 8.1 & -368 & $\operatorname{Cr}(20)$ & 2.74 & 1.31 & 1.22 & 1.22 & 0.72 & $\mathrm{O}(0.9), \mathrm{C}(0.6), \mathrm{H}(1.0)$ \\
\hline $\mathrm{TaN}$ & $c-\mathrm{TaN}^{(\mathrm{e})}$ & 4.43 & 111 & 16.9 & -91 & W (27) & 3.46 & 1.57 & 1.50 & $0.95^{(c)}$ & $0.51^{(c)}$ & $O(0.6), C(0.6)$ \\
\hline WN & $c-\mathrm{W}_{2} \mathrm{~N}$ & 4.24 & 002 & 12.7 & -17 & $W^{(g)}$ & 3.94 & 0.64 & 0.59 & $\mathrm{~N} / \mathrm{A}$ & 0.20 & below detection limits \\
\hline
\end{tabular}

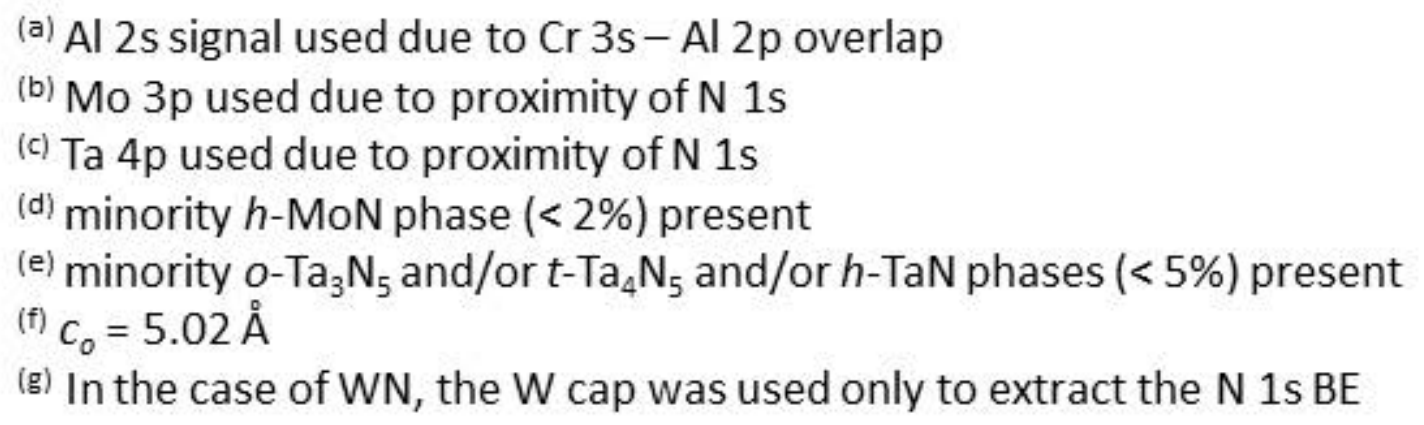

Tab. 1 


\begin{tabular}{|c|c|c|}
\hline $\begin{array}{l}\text { TMN } \\
\text { (capping } \\
\text { metal) }\end{array}$ & $\begin{array}{c}\text { N 1s BE } \\
\text { (capped) } \\
{[\mathrm{eV}]}\end{array}$ & $\begin{array}{c}\text { Main metal line BE } \\
\text { (capped) } \\
{[\mathrm{eV}]}\end{array}$ \\
\hline AIN (Cr) & 397.21 & 74.11 (Al 2p) \\
\hline $\operatorname{SiN}(\mathrm{Cr})$ & 397.87 & 102.11 (Si 2p) \\
\hline $\operatorname{TiN}(\mathrm{Cr})$ & 397.21 & $454.95\left(\mathrm{Ti}_{2} \mathrm{p}_{3 / 2}\right)$ \\
\hline $\mathrm{VN}(\mathrm{Cr})$ & 397.22 & $513.24\left(\mathrm{~V} 2 \mathrm{p}_{3 / 2}\right)$ \\
\hline $\mathrm{CrN}(\mathrm{W})$ & 396.92 & $574.92\left(\mathrm{Cr} 2 \mathrm{p}_{3 / 2}\right)$ \\
\hline $\mathrm{ZrN}(\mathrm{Cr})$ & 397.31 & $179.97\left(\mathrm{Zr} \mathrm{3d}_{5 / 2}\right)$ \\
\hline $\mathrm{NbN}(\mathrm{Cr})$ & 397.56 & $203.99\left(\mathrm{Nb} \mathrm{3d}_{5 / 2}\right)$ \\
\hline $\operatorname{MoN}(\mathrm{W})$ & 397.79 & $228.42\left(\mathrm{Nb} \mathrm{3d}_{5 / 2}\right)$ \\
\hline $\mathrm{HfN}(\mathrm{Cr})$ & 397.19 & $15.73\left(\mathrm{Hf}_{4 f_{7 / 2}}\right)$ \\
\hline $\operatorname{TaN}(\mathrm{W})$ & 397.54 & $23.89\left({\left.\mathrm{Ta} 4 f_{7 / 2}\right)}\right)$ \\
\hline WN & 397.94 & $\mathrm{~N} / \mathrm{A}$ \\
\hline
\end{tabular}

Tab. 2 


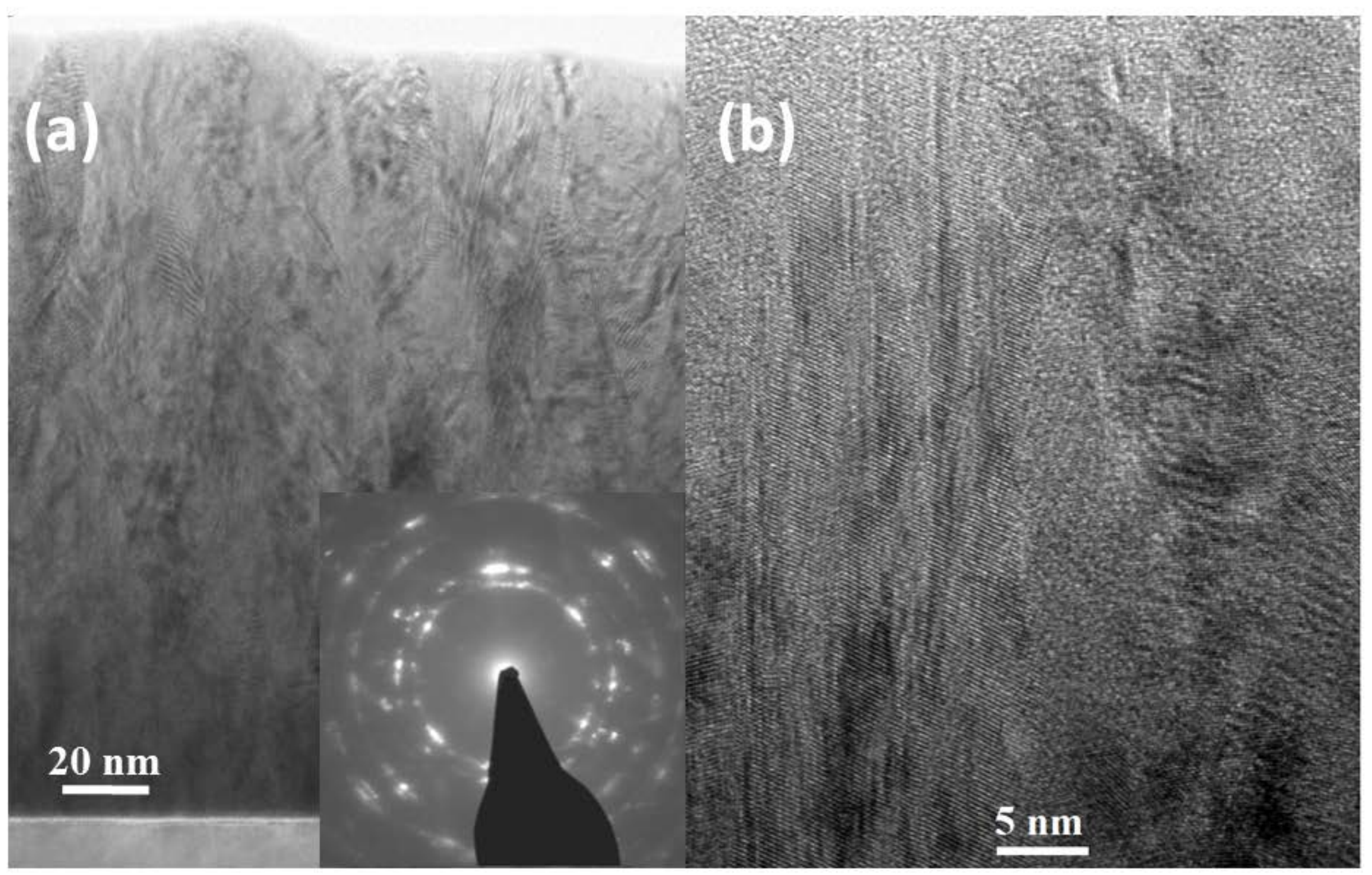

Fig. 1 


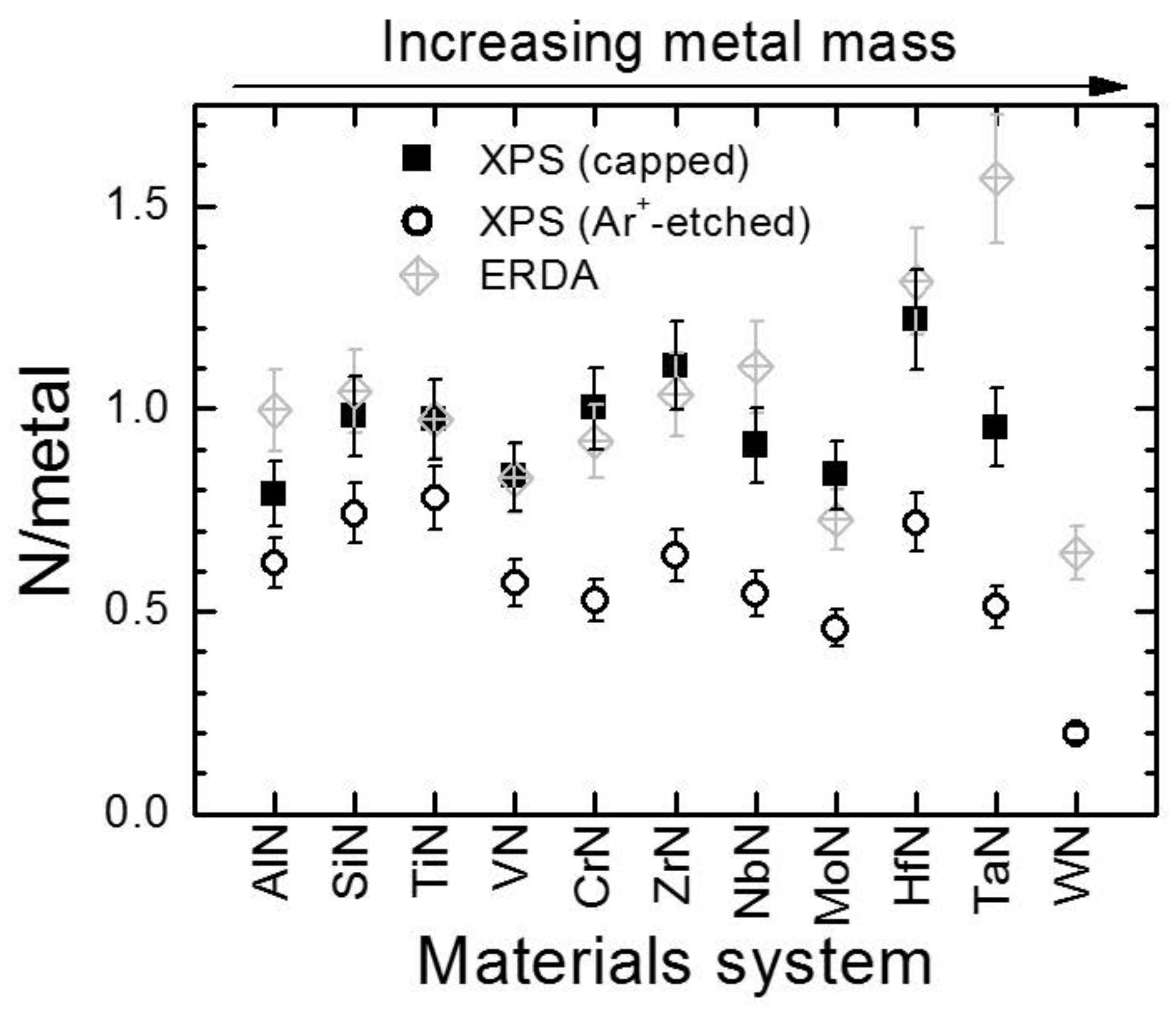

Fig. 2 


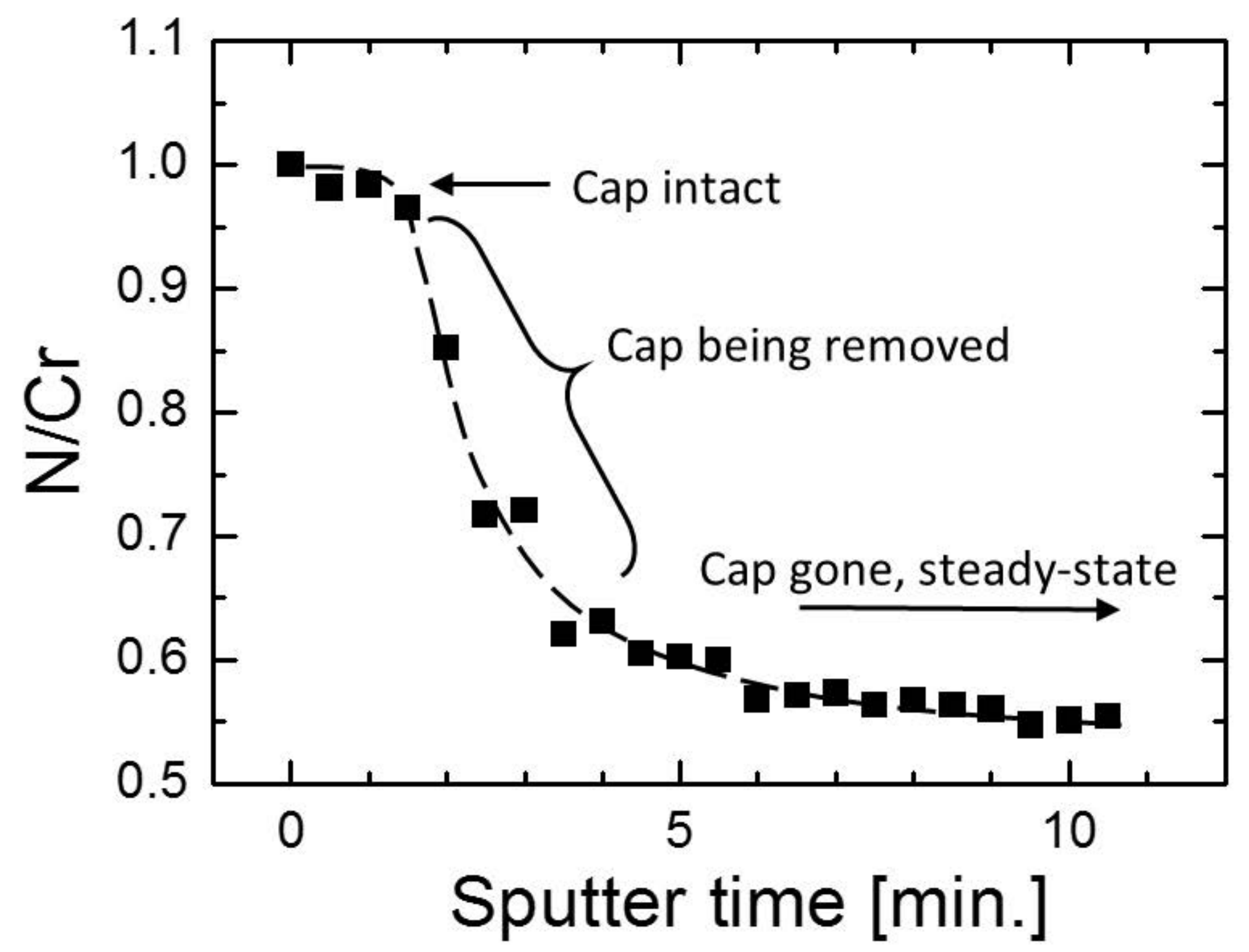

Fig. 3 


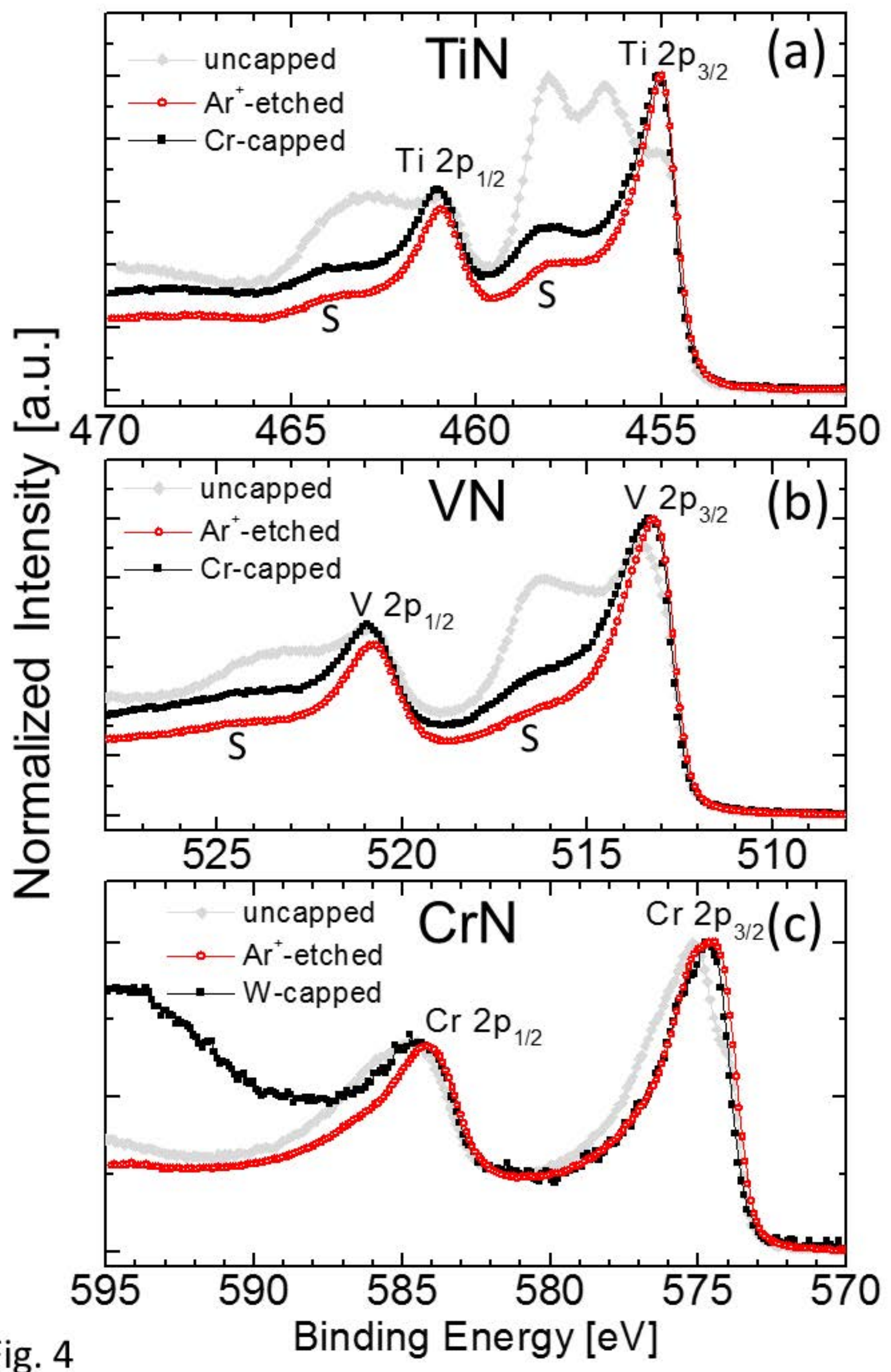

Fig. 4 


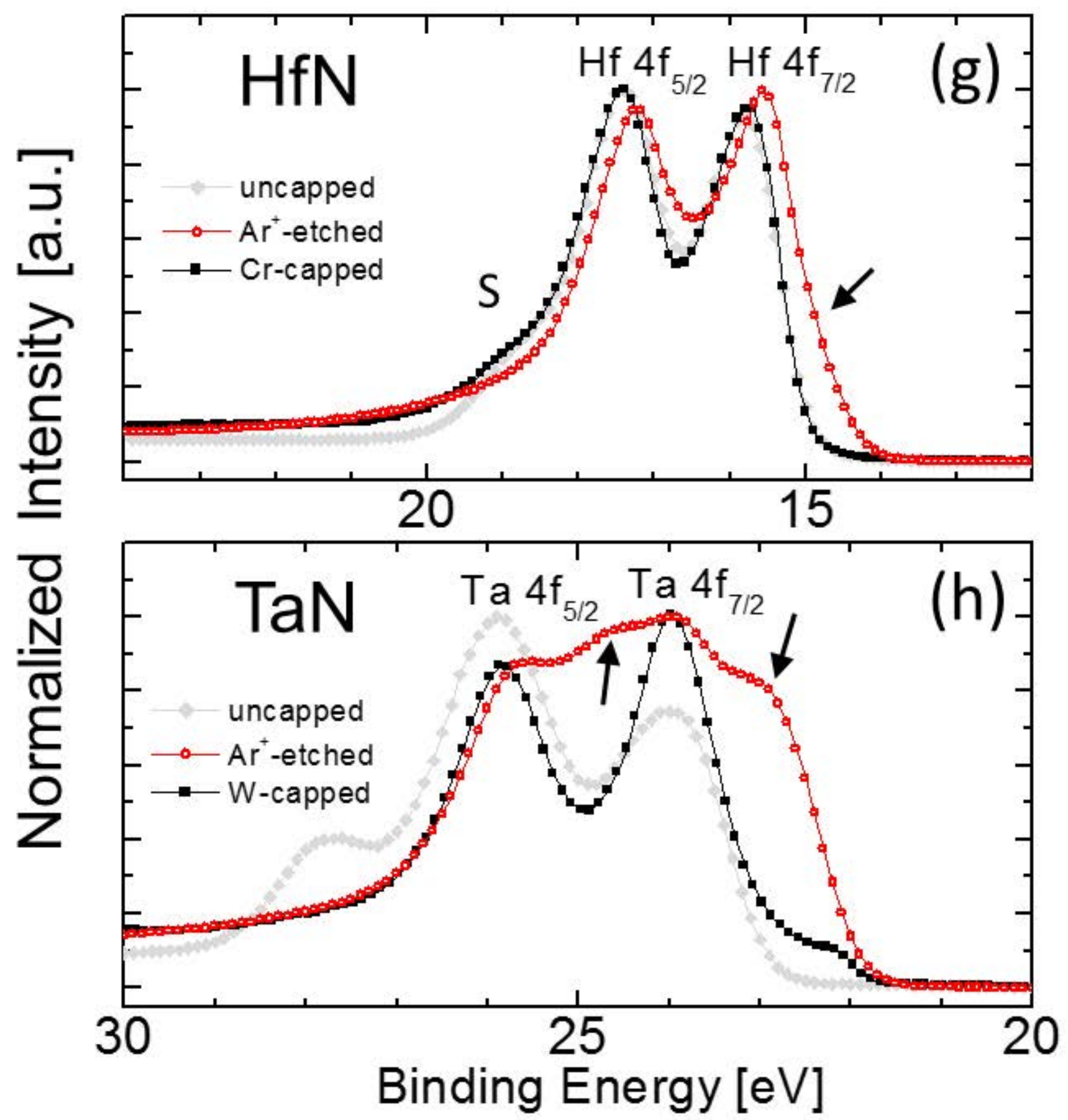

Fig. 4 


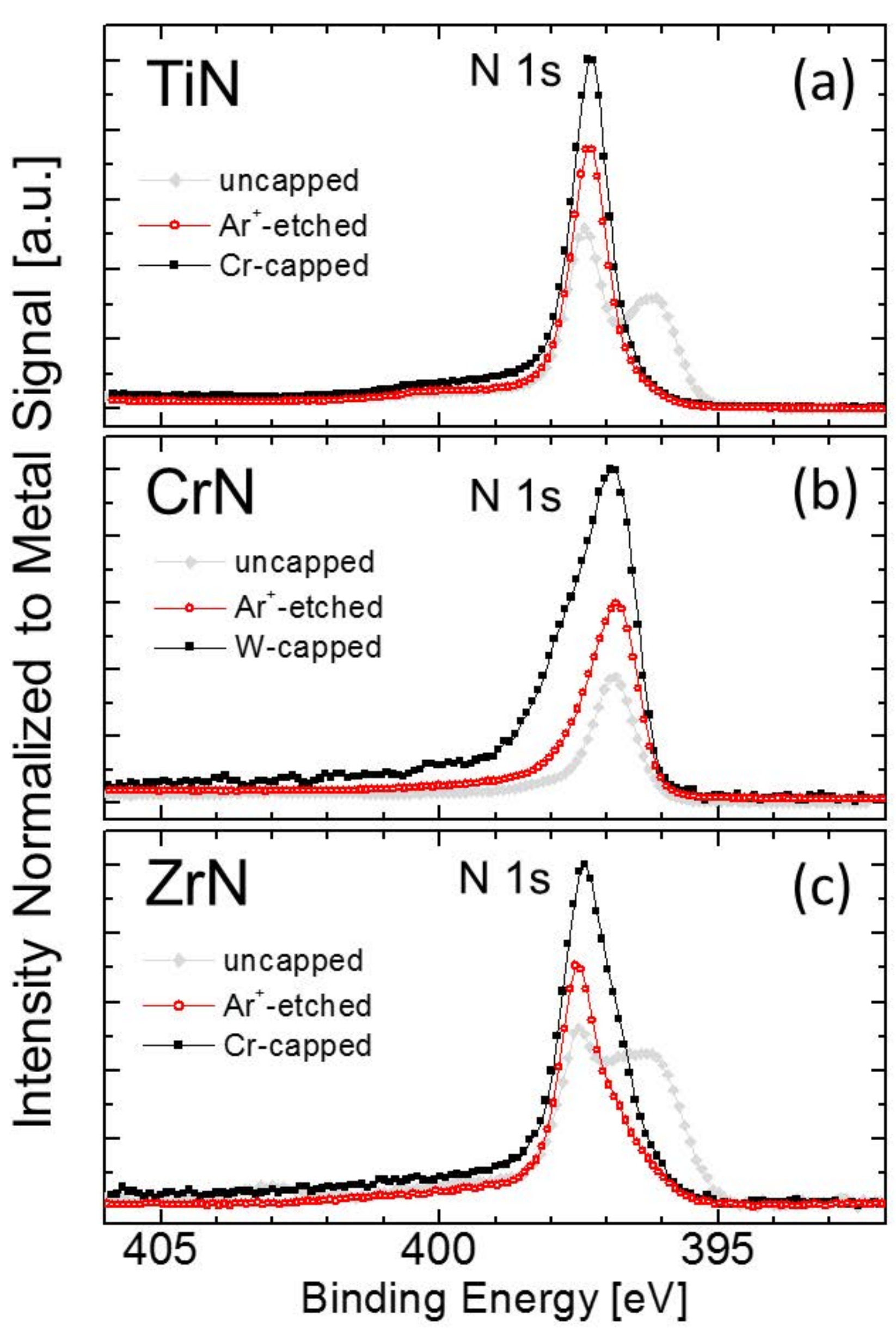

Fig. 5 


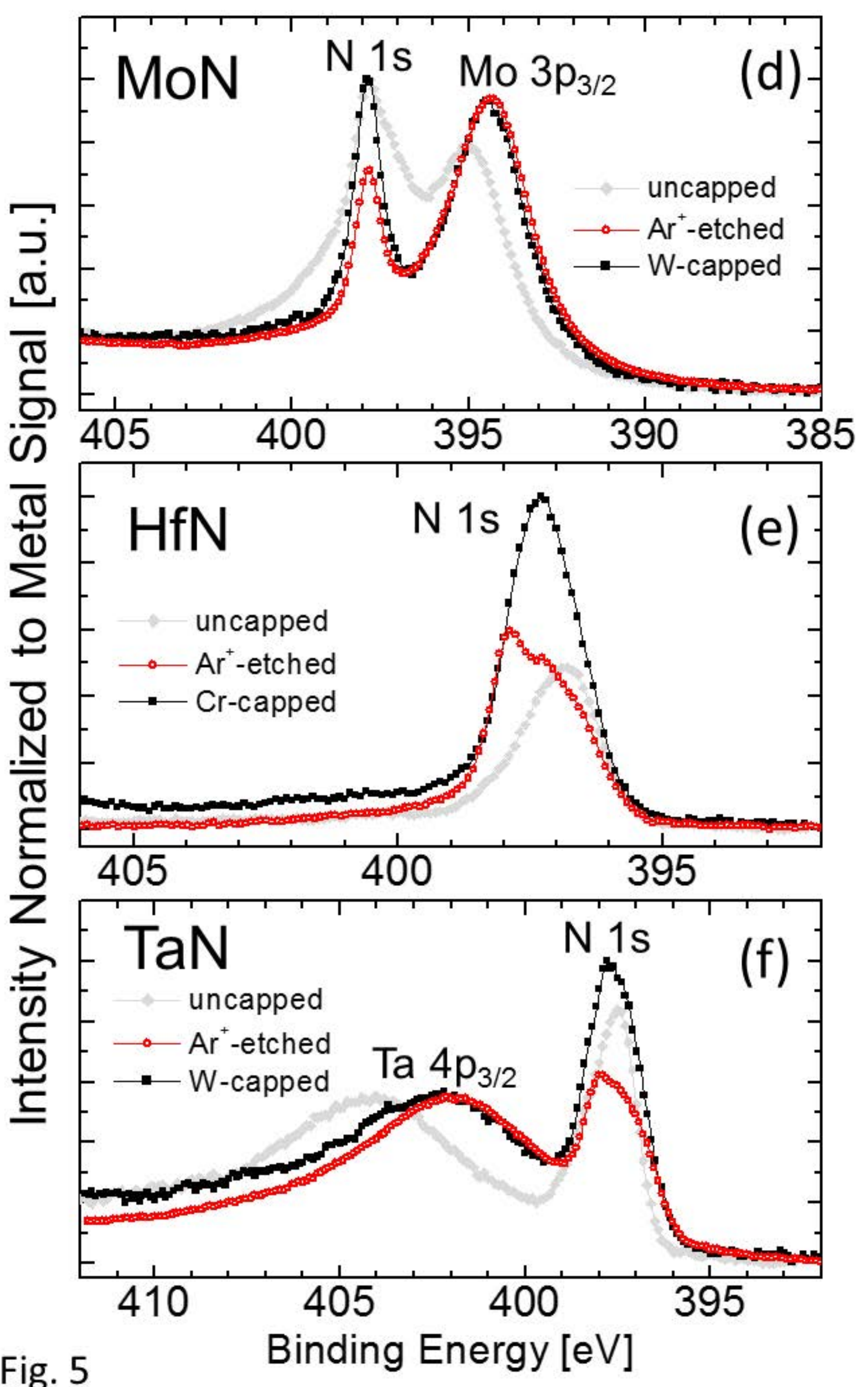



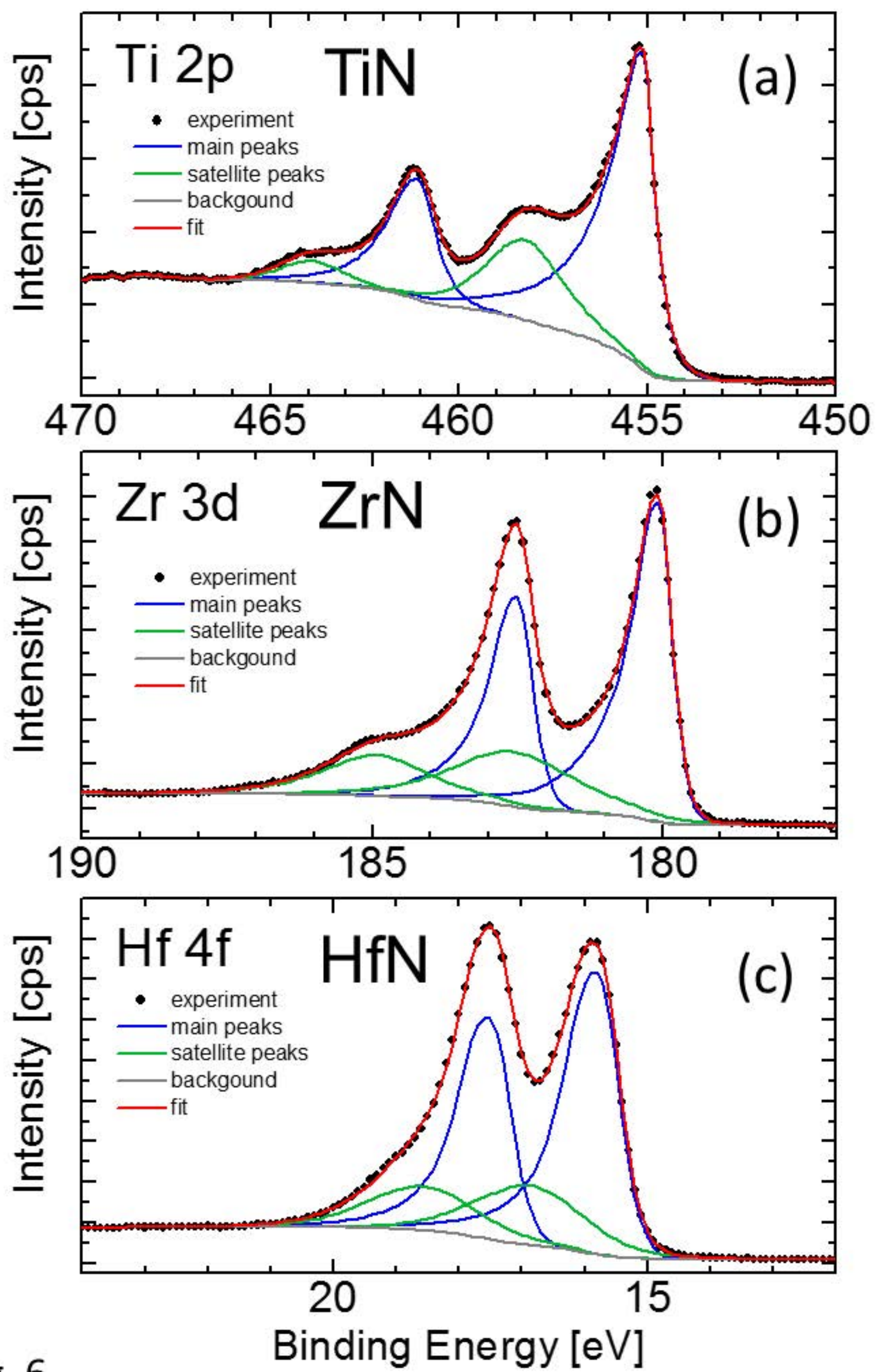

Fig. 6 


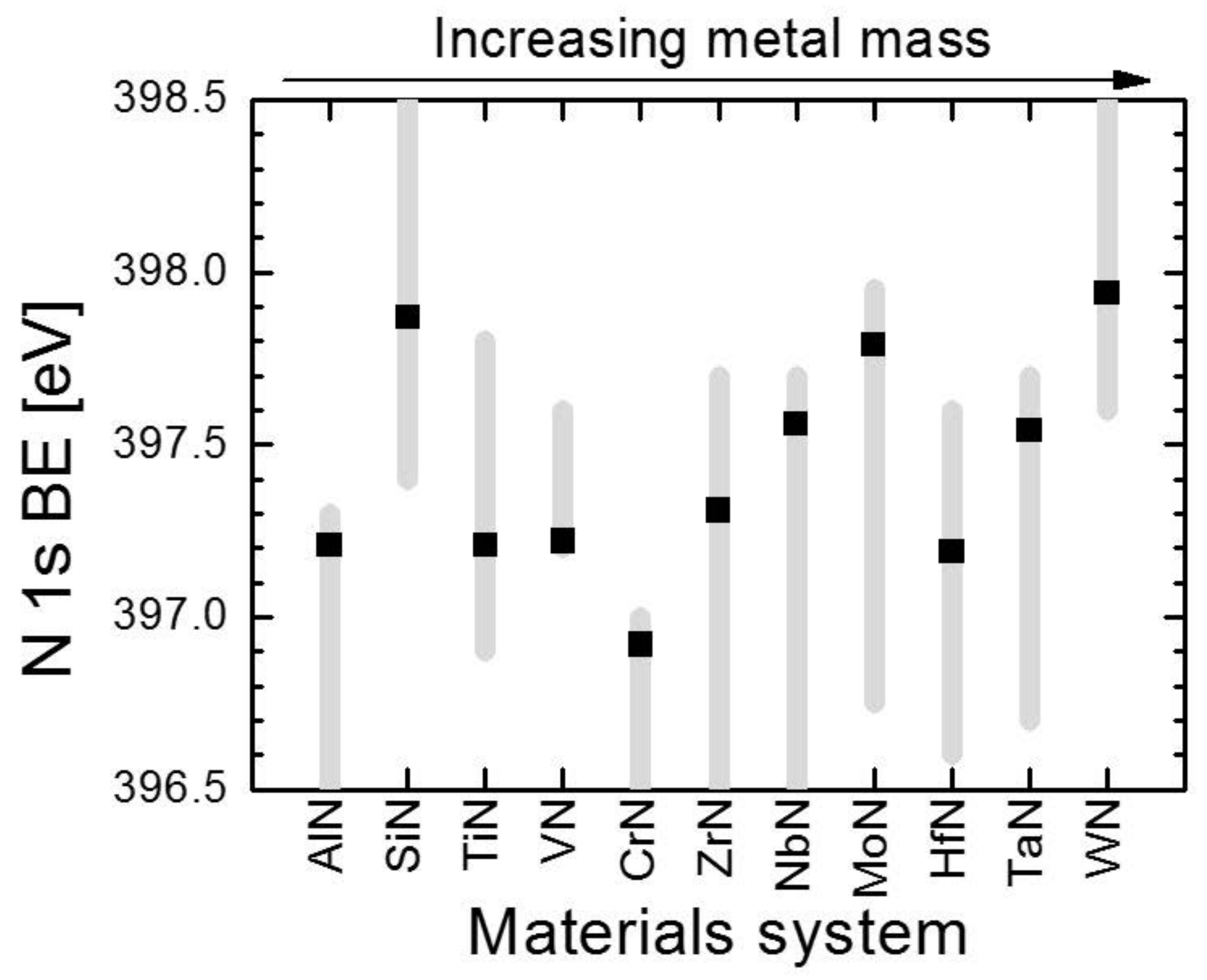

Fig. 7 